\title{
An Evaluation of a Methodology for Seasonal Soil Water Forecasting for Australian Dry Land Cropping systems
}

Andrew W Western ${ }^{1}$, Kithsiri B Dassanayake ${ }^{1}$, Kushan C. Perera ${ }^{1}$, Robert M Argent ${ }^{2}$, Oscar Alves ${ }^{2}$, Griffith Young ${ }^{2}$, Dongryeol Ryu ${ }^{1}$

${ }^{1}$ Department of Infrastructure Engineering, the University of Melbourne, Parkville, VIC 3010, Australia

${ }^{2}$ Bureau of Meteorology, 700 Collins St, Docklands VIC 3208, Australia

Corresponding author:

Andrew W Western, Department of Infrastructure Engineering, the University of Melbourne, Parkville, VIC 3010, Australia.

T: +61 38344 7305, M: 0408577 855, E: a.western@unimelb.edu.au

Highlights:

- We produce ensemble outlooks of plant available soil water (PASW)

- PASW outlooks have some skill in predicting above/below median conditions for 3-6 months

- PASW ensembles are more skilful than climatology for 1-3 lead months

- PASW outlook skill mostly derives from initial soil water conditions 


\section{Abstract}

Soil water is a critical resource in many rain-fed agricultural systems. Climate variability represents a significant risk in these systems, which has been addressed in the past through seasonal weather outlooks. This study undertakes a pilot assessment of the potential to extend seasonal weather outlooks to plant available soil water (PASW). We analyse 20 sites in the southeast Australian wheat belt using seasonal weather outlooks from the Predictive Ocean-Atmosphere Model for Australia (POAMA); ; which is (the operational seasonal model of the Australian Bureau of Meteorology), which were downscaled and used in conjunction with the Agricultural Production Simulator (APSIM). Hindcast rainfall, potential evapotranspiration (PET) and PASW outlooks were produced on a monthly basis for 33 years at a point scale. The outlooks were assessed using a range of ensemble verification tools. The results showed hit rates that exceededoutperformed climatology for rainfall and PET in the short-term (0-2 months), and for PASW with longer lead times (2-5 months). The results showed hit rates for rainfall and $P E T$ that exceeded climatology in the short term ( $(02$ months) and for longer lead times (2 5 months) for PASW. Continuous rank probability skill scores (CRPSS) were generally statistically worse than climatology for rainfall and PET and statistically better than climatology for PASW for over 1-3 months for PASW. The influence of initial soil water is seasonally dependent, with longer dependence in low evapotranspiration periods. Improved weather model downscaling approaches would transition to climatology and could improve both weather and PASW outlooks. PASW outlooks were strongly reliant on initial conditions, indicating the importance of understanding current soil water status, which needs to be interpreted in a seasonal context as its influence varies over the year. Expanded operational soil water monitoring would be important if PASW outlooks are to become routine.

Keywords: Seasonal forecast, Soil moisture, Dry land agriculture, POAMA, APSIM 


\section{Introduction}

Water is the key limiting factor for productivity of natural and agricultural ecosystems in many places (Nemani et al., 2003). Soil water constitutes only about $0.005 \%$ of global water resources; however, it is not only an important part of the terrestrial hydrological cycle but also a key control variable in numerous landscape processes and feedback loops within climate systems (Seneviratne et al., 2010). In this paper, we concentrate on soil water in the root zone.

A soil's ability to retain water is an important hydrological property as it strongly influences the availability of water to plants over dry periods. This in turn influences a variety of biophysical processes important in both the water cycle and in the primary productivity of plants (Western et al., 2002). Root zone soil water is the primary water resource for dry land agriculture; the largest form of agriculture in the world. Over $80 \%$ (1.5billion ha) of the global cultivated land area is under rain-fed farming and it contributes about $60 \%$ of world's crop production (FAO, 2015; Sharma, 2011). In Australia nearly $75 \%$ of agricultural enterprises are rain-fed systems that represent about $99.5 \%$ of the total farmland (Australian Bureau of Statistics, 2015).

Dry Land agricultural systems are inherently risky enterprises, particularly in Australia, due to uncertainties associated with climate variability i.e. highly variable rainfall, recurrent dry spells and droughts. A number of critical management decisions in dry land cropping such as sowing and fertiliser application rely on rainfall and/or soil water status, hence the level of soil water storage is a key piece of information that could help farmers make more informed decisions on the management of rain-fed cropping systems. Further, adding to the complexity, under changing climate; ${ }_{;}$crop production potential and cropping inputs are likely to be subject to greater instability and uncertainty due to increased seasonal variability.

Short-term to seasonal prediction of soil water availability based on climate outlooks has the potential to help optimize production and maintaining profitability from dryland agricultural systems. Relevant decisions include logistics such as scheduling of planting, tactical crop management in terms of fertilizer and pesticide use, decisions about crop type, crop sequence, crop rotation, and land use and adaptation of current systems (Meinke and Stone, 2005). 
The need to make decisions based on limited and uncertain information means that farmers face two challenges. First, decisions such as crop type, planting time, sowing densities or rate of nitrogen fertilisation have to be made prior to the growing season and in the face of climatic uncertainty. Secondly, devising a strategy that balancesbalancing the cost to farmers of the use using ef suboptimal inputs and the cost of failing to capitalise on favourable seasons such asby leaving a field fallow to increase soil water storage (Hayman, 2011). Management of these risks could be informed by providing two types of information to farmers for decision making to reduce climate related risk. The first is the presentation of historical data that allows farmers to extend their knowledge base due to testing of different crop related scenarios. The second is forecasts of the coming season that can be presented in either a probabilistic or a categorical manner (Hansen, 2002; Hayman et al., 2007; Meinke and Stone, 2005). While there are many important factors in addition to climate variability that farmers consider in their decision-making, agricultural decisions at a range of temporal and spatial scales can benefit from targeted climate forecasts.

There are known climatic phenomena that contribute to rainfall variability in Australia and are relevant to farmers' decision making (Meinke and Stone, 2005). These include the Madden-Julian Oscillation (MJO) (Meinke and Stone, 2005), El Nino-Southern Oscillation ENSO (Hansen, 2002; Meinke and Stone, 2005), the Quasi-Biennial Oscillation (QBO), the Antarctica Circumpolar Wave (ACW) and the Inter-decadal Pacific Oscillation (IPO) (Meinke and Stone, 2005). Conventional seasonal climate forecasts ( $\mathrm{SCFs}$ ) are statistical in nature and forecast information is most completely characterized by a probability density function (Tippett et al., 2007). These forecasts were based on teleconnections to the above phenomena, particularly ENSO. With recent advances in computing technology, physicsbased SCFs have become more accurate, relevant and offer great potential to mitigate risks and take advantage of expected favourable climatic conditions, particularly for climate dependent enterprises such dry land agriculture (Paull, 2002). With recent advances in computing technology, physies based SCFs have become more accurate, relevant and offer great potential particularly for climate dependent enterprises such dry land agriculture to mitigate risks and also take advantage of expected favourable elimatic conditions (Paull, 2002). SCFs have become an important aspect of decision making for 
farmers since the 1980 s as they offer potential for improving management and planning of crop production (Hansen, 2002; Hayman et al., 2007; Nelson et al., 2002).

The SCFs of the Australian Bureau of Meteorology are currently based on the Predictive Ocean Atmosphere Model for Australia (POAMA), which is comprised of a coupled ocean-atmosphere model, a data assimilation system and a strategy for generating forecast ensembles. In Australia, the Bureau of Meteorology provides seasonal outlook forecasts for streamflow and climatic variables including SOI, rainfall and temperature, which are considered to be important for farmers in their decision makings (Bureau of Meteorology, 2014). However, seasonal soil water availability has been a key missing piece of information that could assist dry land farmers to make better decisions well in advance $_{2}$ minimising the potential risks and associated financial penalties.

A number of agencies in the-North America and Europe (The Soil Climate Analysis Network (SCAN); of-National Water and Climate Center, USDA; European Environment Agency; Natural Resources Canada) provide current status of soil water as low resolution map products. In the meantime, the US National Weather Service has developed forecasting tools, which are able to predict soil water for the next fortnight, upcoming month and for seasons out to aup to 12 months period-in advance. The 14 day soil water forecast is based on the National Weather Service Global Forecast System (GFS) global model (Environmental Modeling Center, 2003) $)_{2}$ while monthly and seasonal forecasting tools are based on the Constructed Analog on Soil Moisture in the top 1.6m of the soil profile (van den Dool et al., 2003). The GFS model runs at a resolution of $0.5^{\circ} \times 0.5^{\circ}$ for 16 day forecast lead times, but with decreasing spatial and temporal resolution over time and the volumetric soil water content is limited to a layer of $10 \mathrm{~cm}$ from the surface.

More recently, (-Dirmeyer, (2013) assessed NOAA's Coupled Forecast System v2 (CFS v2) forecasts of precipitation and soil water outlooks for four soil layers (0-10, 10-40, 40-100 and 100-200cm). Using a rank probability skill score for tercile forecasts, they found rapidly declining skill in precipitation and regionally dependent declines in layer 2 soil moisture forecasts that show some skill up to five months. These assessments were at the model grid scale. (-Spennemann et al.; (2017) also consider CFS v2 soil water forecasts for the top $1 \mathrm{~m}$ of the soil profile, concentrating on south-east 
South America. They find limited skill in precipitation prediction and some skill (assessed by anomaly correlation coefficient) against Global Land Data Assimilation Scheme soil water estimates (top 1m) for the first month in summer and up to 3 months in winter.

The above tools are more applicable at regional to global scales. The other key deficiency of these tools in agricultural decision making is that they do not effectively account for crop water dynamics; soil water is estimated with a monthly scale soil water balance approach (van den Dool et al., 2003). The Centre for Ocean-Land-Atmosphere Studies of George Mason University routinely produce 8day soil water forecast maps for 11 regions around the world based on the Community Climate System Model version 4 (CCSM4) (Gent et al., 2011; Oleson et al., 2010). Again, the spatial resolution of the embedded land and atmospheric models $\left(1.25^{\circ} \mathrm{x} 0.94^{\circ}\right)$ limit the applicability of the predictions at local scales.

While weather dynamics have an important impact on soil water dynamics, those dynamics are modulated by the soil. Water retention characteristics of soils vary significantly across the landscape and also down the soil depth profile (Geroy et al., 2011). Further, soil water storage is also affected by various other factors including land and soil management ${ }_{2}$ and-type of vegetation, and their growth patterns (phenology) and management (BIO Intelligence Service, 2014; Haruna and Nkongolo, 2013). To make soil water outlooks more relevant and meaningful for agricultural production systems, these key aspects should be integral components of the forecasting processes.

To further our understanding of the potential of dynamical soil water outlooks, this paper assesses the skill of soil water outlooks made using a combination of the APSIM crop model and POAMA seasonal outlooks, which are downscaled to individual weather stations. For this initial approach we selected the Agricultural Production Systems Simulator (APSIM), because it is the most widely used and well parameterized cropping systems model in Australia and elsewhere, and it is well calibrated for large number $\underline{\text { s }}$ of sites across various agro-ecological regions of Australia (Holzworth et al., 2014). Here we develop a workflow for generating site scale estimates of current soil water conditions and seasonal soil water outlooks. These outlooks are assessed for predictive skill utilising a 33 year hindcast period using modelled soil water based on historical weather observations. 


\section{Methodology}

\subsection{Study area}

This study covered a range of representative sites in the South-East Australian wheat belt (Figure 1). The sites correspond to weather stations run by the Bureau of Meteorology, Australia (Table 1). Soil properties at these sites were selected to represent the dominant cropping soil in the area. This was done by combining the online soil map and profile information from the Victorian Soil and Land Survey of 'Victorian Resources Online' (http://vro.depi.vic.gov.au/dpi/vro/soilsurv.nsf/HTML/Index) and NSW soil and land information data from 'eSPADE' (http://www.environment.nsw.gov.au/eSpadeWebApp/) for each state-with APSIM's soil database 'Apsoil' (https://www.apsim.info/Products/APSoil.aspx), the APSIM soils database. Voluntarily reported APSoil sites are generally user calibrated sites for previous APSIM simulations and contain detailed soil input parameter information required for simulations along with the geographical location of the simulated site. Once a wheat soil type was identified from the online soil databases, the best matching soil profile was selected from the APSoil database. Essentially, we have combined local soils with a nearby weather station to form the simulation "sites" used in the study. 
1 Table 1: Location details of 20 study sites including relevant soil types and the nearest meteorological stations used for climatology of each site. Abbreviations 2 in the Soil column are: $\mathrm{CL}=$ clay loam, $\mathrm{LS}=$ loamy sand, $\mathrm{SCL}=$ sandy clay loam, Clay = clay. and $-\mathrm{T}$ the classifications follow the Australian Soil Classification 3 (Isbell, 1996).

\begin{tabular}{|c|c|c|c|c|c|c|c|c|c|c|c|c|c|c|c|c|}
\hline \multirow{3}{*}{$\begin{array}{l}\text { Sit } \\
\mathrm{e} \\
\text { No }\end{array}$} & \multirow{3}{*}{ State } & \multirow{3}{*}{$\begin{array}{l}\text { NRM } \\
\text { Region }\end{array}$} & \multirow[t]{3}{*}{ Site Name } & \multirow[t]{3}{*}{ Nearest Town } & \multirow{3}{*}{$\begin{array}{l}\text { APSoil } \\
\text { No }\end{array}$} & \multirow[t]{3}{*}{ Soil } & \multirow{3}{*}{$\begin{array}{l}\text { Stat'n } \\
\text { ID }\end{array}$} & \multirow[t]{3}{*}{ Met Station } & \multirow[t]{3}{*}{ Lat } & \multirow[t]{3}{*}{ Lon } & \multirow{3}{*}{$\begin{array}{l}\text { Elevatio } \\
\mathrm{n}(\mathrm{m})\end{array}$} & \multirow{3}{*}{$\begin{array}{l}\text { Annual } \\
\text { Rainfal } \\
1(\mathrm{~mm}) \\
\end{array}$} & \multicolumn{4}{|c|}{ Mean Daily Temperature } \\
\hline & & & & & & & & & & & & & \multicolumn{2}{|c|}{ January } & \multicolumn{2}{|c|}{ July } \\
\hline & & & & & & & & & & & & & $\operatorname{Max}$ & Min & $\operatorname{Max}$ & Min \\
\hline 1 & VIC & Mallee & $\begin{array}{l}\text { Reedy } \\
\text { Dam }\end{array}$ & Birchip & 732 & $\begin{array}{l}\text { Calcarosol } \\
\text { (CL) }\end{array}$ & 77008 & $\begin{array}{l}\text { Birchip } \\
\text { (Woodlands) }\end{array}$ & $\begin{array}{l}- \\
35.92\end{array}$ & $\begin{array}{l}142.8 \\
5\end{array}$ & 100 & 350 & 31.4 & 14.8 & 14.2 & 3.9 \\
\hline 2 & VIC & Mallee & Walpeup & Walpeup & 725 & $\begin{array}{l}\text { Calcarosol } \\
\text { (LS) }\end{array}$ & 76047 & $\begin{array}{l}\text { Ouyen } \\
\text { (Post Office) }\end{array}$ & $\begin{array}{l}- \\
35.07\end{array}$ & $\begin{array}{l}142.3 \\
1\end{array}$ & 65 & 319 & 32.5 & 15.8 & 15.3 & 4.5 \\
\hline 3 & VIC & Mallee & Jil Jil & Birchip & 722 & $\begin{array}{l}\text { Calcarosol } \\
\text { (SCL) }\end{array}$ & 77007 & $\begin{array}{l}\text { Birchip } \\
\text { (Post Office) }\end{array}$ & $\begin{array}{l}- \\
35.98\end{array}$ & $\begin{array}{l}142.9 \\
2\end{array}$ & 102 & 353 & 31.2 & 14.7 & 14.1 & 3.9 \\
\hline 4 & VIC & Mallee & Meering & Quambatook & 733 & $\begin{array}{l}\text { Sodosol } \\
(\mathrm{CL})\end{array}$ & 79075 & Quambatook & $\begin{array}{l}- \\
35.84\end{array}$ & $\begin{array}{l}143.5 \\
1\end{array}$ & 145 & 408 & 29.8 & 13.5 & 13.3 & 4.0 \\
\hline 5 & VIC & Wimmera & Sheep Hills & Warracknabeal & $570-Y \mathrm{P}$ & $\begin{array}{l}\text { Vertosol } \\
\text { (Clay) }\end{array}$ & 78000 & Warracknabeal & - & $\begin{array}{l}142.3 \\
3\end{array}$ & 116 & 375 & 30.6 & 13.7 & 13.8 & 3.8 \\
\hline 6 & VIC & Wimmera & Goroke & Goroke & $571-Y P$ & $\begin{array}{l}\text { Red } \\
\text { Sodosol } \\
\text { (CL) }\end{array}$ & 79017 & $\begin{array}{l}\text { Goroke } \\
\text { (Post Office) }\end{array}$ & $\begin{array}{l}- \\
36.72\end{array}$ & $\begin{array}{l}141.4 \\
7\end{array}$ & 162 & 459 & 29.2 & 12.1 & 13.2 & 3.9 \\
\hline 7 & VIC & Wimmera & Nhill & Nhill & 750 & $\begin{array}{l}\text { Brown } \\
\text { Sodosol } \\
(\mathrm{CL})\end{array}$ & 78040 & Nhill (Woorak) & $\begin{array}{l}- \\
36.29\end{array}$ & $\begin{array}{l}141.7 \\
4\end{array}$ & 140 & 391 & 30.3 & 13.0 & 13.7 & 3.7 \\
\hline 8 & VIC & Wimmera & Lubeck & Lubeck & 746 & $\begin{array}{l}\text { Vertosol } \\
\text { (Clay) }\end{array}$ & 79010 & Drung Drung & $\begin{array}{l}- \\
36.78\end{array}$ & $\begin{array}{l}142.3 \\
9\end{array}$ & 146 & 424 & 29.4 & 12.9 & 13.2 & 3.8 \\
\hline 9 & VIC & $\begin{array}{l}\text { Glenelg- } \\
\text { Hopkins }\end{array}$ & Dunkeld & Dunkeld & 632-YP & $\begin{array}{l}\text { R/B } \\
\text { Chromosols }\end{array}$ & 89011 & Dunkeld & $\begin{array}{l}- \\
37.66\end{array}$ & $\begin{array}{l}142.3 \\
4\end{array}$ & 250 & 656 & 26.3 & 11.2 & 12.2 & 4.2 \\
\hline
\end{tabular}




\begin{tabular}{|c|c|c|c|c|c|c|c|c|c|c|c|c|c|c|c|c|}
\hline 10 & VIC & $\begin{array}{l}\text { Glenelg- } \\
\text { Hopkins }\end{array}$ & Westmere & Lake Bolac & 555-YP & $\begin{array}{l}\text { Brown } \\
\text { Sodosol }\end{array}$ & 89016 & $\begin{array}{l}\text { Lake Bolac } \\
\text { (Post Office) }\end{array}$ & $\begin{array}{l}- \\
37.71\end{array}$ & $\begin{array}{l}142.8 \\
4\end{array}$ & 220 & 556 & 26.4 & 11.4 & 12.3 & 4.2 \\
\hline 11 & VIC & $\begin{array}{l}\text { Corangamit } \\
\mathrm{e}\end{array}$ & Murdeduke & Winchelsea & 825 & $\begin{array}{l}\text { Brown } \\
\text { Sodosol }\end{array}$ & 90005 & $\begin{array}{l}\text { Beeac } \\
\text { (Post Office) }\end{array}$ & -38.2 & $\begin{array}{l}143.6 \\
4\end{array}$ & 120 & 618 & 25.3 & 12.5 & 12.9 & 5.5 \\
\hline 12 & VIC & $\begin{array}{l}\text { Corangamit } \\
\text { e }\end{array}$ & Skipton & Skipton & GL157 & $\begin{array}{l}\text { Brown } \\
\text { Chromosol } \\
\text { (CL) }\end{array}$ & 89025 & $\begin{array}{l}\text { Skipton } \\
\text { (Post Office) }\end{array}$ & $\begin{array}{l}- \\
37.69\end{array}$ & $\begin{array}{l}143.3 \\
7\end{array}$ & 295 & 576 & 26.2 & 11.5 & 11.7 & 3.9 \\
\hline 13 & VIC & $\begin{array}{l}\text { North } \\
\text { Central }\end{array}$ & Elmore & Elmore & 567 & $\begin{array}{l}\text { Red } \\
\text { Sodosol }\end{array}$ & 81041 & Raywood & - & $\begin{array}{l}144.2 \\
1\end{array}$ & 127 & 427 & 30.3 & 14.5 & 13.3 & 3.3 \\
\hline 14 & VIC & $\begin{array}{l}\text { North } \\
\text { Central }\end{array}$ & Kerang & KERANG & 746 & $\begin{array}{l}\text { Vertosol } \\
\text { (Clay) }\end{array}$ & 80023 & Kerang & $\begin{array}{l}- \\
35.72\end{array}$ & $\begin{array}{l}143.9 \\
2\end{array}$ & 78 & 388 & 31.8 & 15.6 & 14.3 & 4.1 \\
\hline 15 & VIC & North East & Boorhaman & Boorhaman & 554-YP & $\begin{array}{l}\text { Red } \\
\text { Sodosol } \\
\text { (CL) }\end{array}$ & 82006 & Boorhaman & $\begin{array}{l}- \\
36.22\end{array}$ & $\begin{array}{l}146.2 \\
8\end{array}$ & 142 & 579 & 31.8 & 14.9 & 13.0 & 2.8 \\
\hline 16 & VIC & North East & Boorhaman & Boorhaman & 595-YP & $\begin{array}{l}\text { Red } \\
\text { Dermosol }\end{array}$ & 82006 & Boorhaman & $\begin{array}{l}- \\
36.22\end{array}$ & $\begin{array}{l}146.2 \\
8\end{array}$ & & 579 & 31.8 & 14.9 & 13.0 & 2.8 \\
\hline 17 & NSW & Riverina & Coolamon & Coolamon & 175 & $\begin{array}{l}\text { Red } \\
\text { Chromosol }\end{array}$ & 74033 & $\begin{array}{l}\text { Coolamon } \\
\text { Post Office) }\end{array}$ & $\begin{array}{l}- \\
34.82\end{array}$ & $\begin{array}{l}147.2 \\
0\end{array}$ & 310 & 501 & 32.3 & 16.8 & 13.0 & 3.0 \\
\hline 18 & NSW & Riverina & Goolgowi & Griffith & 697 & $\begin{array}{l}\text { Sandy clay } \\
\text { loam }\end{array}$ & 75041 & $\begin{array}{l}\text { Griffith } \\
\text { (Air Port) }\end{array}$ & $\begin{array}{l}- \\
34.25\end{array}$ & $\begin{array}{l}146.0 \\
7\end{array}$ & 144 & 409 & 33.2 & 17.6 & 14.5 & 3.5 \\
\hline 19 & NSW & Riverina & Tarcutta & Tarcutta & 178 & $\begin{array}{l}\text { Brown } \\
\text { Chromosol }\end{array}$ & 72042 & $\begin{array}{l}\text { Tarcutta } \\
\text { (Post Office) }\end{array}$ & $\begin{array}{l}- \\
35.28\end{array}$ & $\begin{array}{l}147.7 \\
4\end{array}$ & 232 & 648 & 32.0 & 15.8 & 12.9 & 2.5 \\
\hline 20 & NSW & Riverina & Bimbie & Euston & 334 & Sandy loam & 49023 & $\begin{array}{l}\text { Euston } \\
\text { (Benington) }\end{array}$ & - & $\begin{array}{l}142.9 \\
1\end{array}$ & 64 & 299 & 33.0 & 16.8 & 15.5 & 4.2 \\
\hline
\end{tabular}




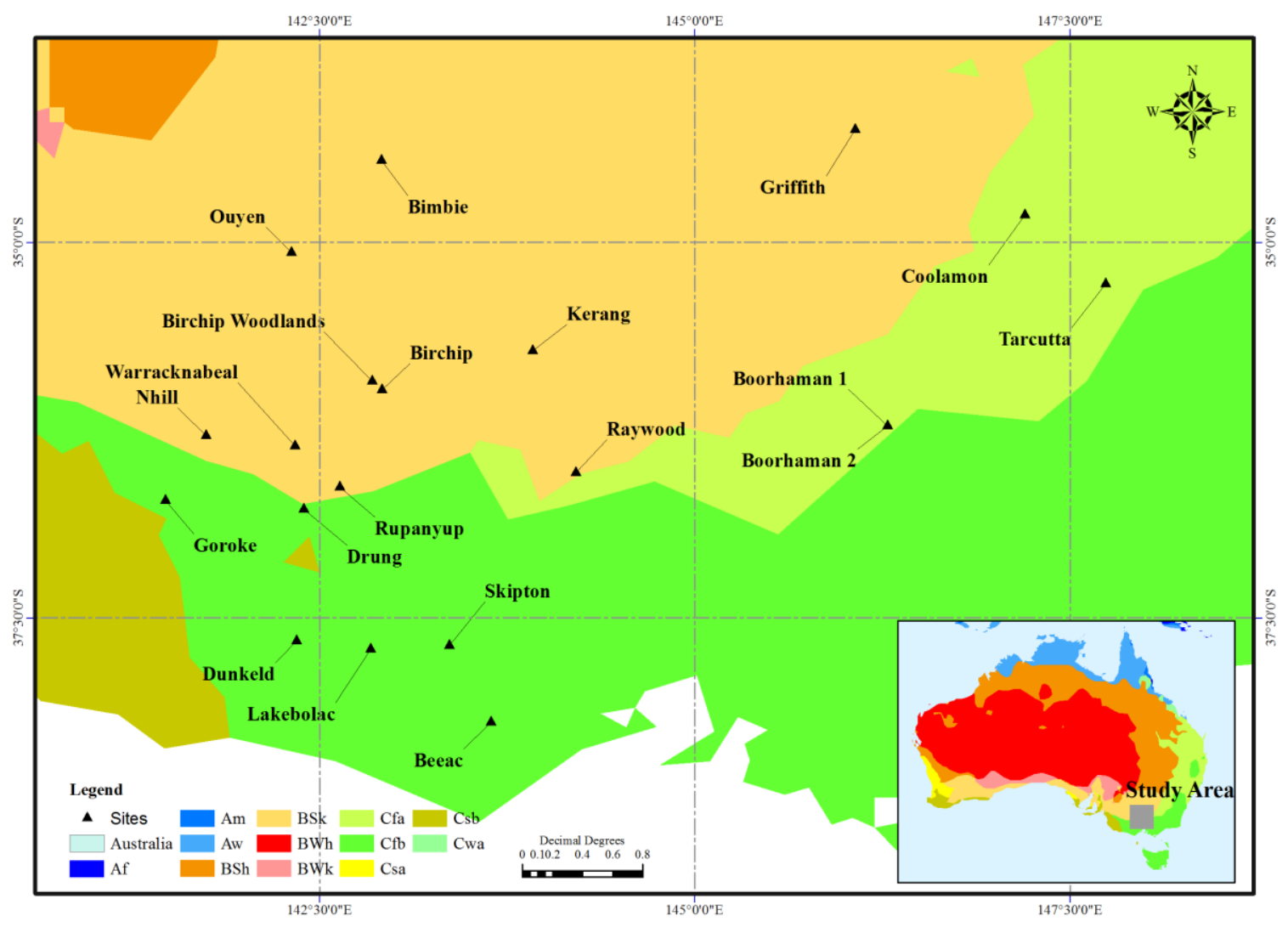

Figure 1. Study sites marked on the Köppen Climate map (Peel et al., 2007). Study sites extend across BSk, Cfa and Cfb climate types.

\subsection{Site Climatology}

Historical daily climate data for the selected 20 meteorological stations were obtained from the enhanced climate database ${ }_{\overline{5}}$ 'SILO', hosted by the Science Delivery Division of the Queensland Department of Science, Information Technology and Innovation (DSITI) of Australia. SILO maintains Australian climate data from 1889 (current to yesterday), in a number of ready-to-use formats, suitable for research and climate applications. We used APSIM ready patched point datasets (Jeffrey et al., 2001) for 39 years (5 years for warm-up plus 33 years of hindcast information) from 1976 to 2014 for our work. SILO patched point data are meteorological station observations with missing or potentially erroneous values 'patched' with interpolated data using nearby stations. Daily climate data series for each site included rainfall $(\mathrm{mm})$, minimum temperature $\left({ }_{-}^{\circ \theta} \mathrm{C}\right)$, maximum temperature $\left({ }_{-}^{\circ} \mathrm{C}\right)$, radiation $\left(\mathrm{MJ} / \mathrm{m}^{2}\right)$, and vapour pressure (hPa). Over the 33 year study period, mean annual rainfall at study sites ranged from $291 \mathrm{~mm}$ to $656 \mathrm{~mm}$ while January mean daily maximum (minimum) temperatures of the 
sites were between 25.3 and $33.2^{\circ} \mathrm{C}\left(11.7\right.$ and $\left.15.5^{\circ} \mathrm{C}\right)$ and July mean daily maximum (minimum) temperatures were between 11.2 and $17.6^{\circ} \mathrm{C}\left(2.5\right.$ and $\left.5.5^{\circ} \mathrm{C}\right)$.

\subsection{Climate outlook ensembles}

We used daily seasonal weather hindcasts for the 1981-2013 period generated by the POAMA-2 system (version M24) (Hudson et al., 2013), each of which were 270 days long. These ensembles were generated to provide an understanding of model climatology and to enable seasonal forecast skill assessments to be made. POAMA-2 is a coupled atmospheric and ocean model with data assimilation and ensemble generation capabilities. The atmospheric model of POAMA is the BAM (BMRC atmospheric model, version 3.0) with T47 horizontal resolution and 17 vertical levels, while the ocean model is ACOM2 (Australian Community Ocean Model, version 2.0) with a resolution of $2^{\circ}$ in the zonal direction (but $0.5^{\circ}$ at the equator and $1.5^{\circ}$ near the poles) and 25 vertical levels. The system deploys the Atmosphere Land Initialisation Scheme (ALI) for atmosphere/land data assimilation (Hudson et al., 2011) and the POAMA Ensemble Ocean Data Assimilation System (PEODAS) for the Ocean data assimilation (Yin et al., 2011). These assimilation schemes include horizontal wind, temperature and humidity in ALI and ocean temperature, salinity and currents in PEODAS.

POAMA multi-model system employs 3 atmospheric model versions and generates 33 ensemble members at daily time steps for each forecast out to the next 270 days (Hudson et al., 2013), slightly less than 9 complete months. In this study, we used hindcasts on the $1^{\text {st }}$ of each month out to 8 months (that is $0-7$ lead months, where the 0 lead month is constructed from the first $\sim 30$ days of the outlook). This was done-for-1981-2013.

\subsection{APSIM}

We used the Agricultural production Systems Simulator (APSIM) (version $7.7 \mathrm{r} 3615$ ) to produce daily soil water time series for study sites using a variety of different climate forcing some that are discussed later. APSIM also output Priestly-Taylor potential evapotranspiration (Priestley and Taylor, 1972), which was used for both forecast PET based on POAMA simulations, and observed PET based on 
observed weather variables. APSIM is a well-tested and stable biophysical modelling framework widely accepted in Australia and elsewhere in the domain of agricultural systems research. It has been used in a wide range of climatic systems and soil types and is capable of simulating a diverse range of farming systems including dryland and irrigated cropping, pastures and fodder systems and agroforestry systems (Asseng et al., 1998; Kloss et al., 2012; Wang et al., 2009).

The main models in the APSIM framework (includinge soil water, carbon and nutrient cycles, crops/pastures and management 2 that are integrated via a simulation engine for seamless flow of data between modules. It is able to simulate soil and plant water dynamics, and the effects of soil properties and management conditions on plant growth and development and the consequential impacts on soil water availability (Hunt et al., 2006).

APSIM is a point scale model and supports a multi-layer soil profile (typically up to 10 soil layers with user-defined layer thicknesses) with a dynamic root growth profile. It offers two options for modelling the soil water balance and solute movement: (a) SOILWAT, which is a cascading layer model where soil water storage is constrained by retention characteristics (Probert et al., 1998); and (b) APSWIM, which is based on a numerical solution of Richards' equation with a convectiondispersion equation to model solute movement more effectively (Keating et al., 2003). We deployed the former option due to its simplicity, lower computational cost and because solute movement was not targeted in the current study.

APSIM also has advantages in its ability to represent the effects of plant growth dynamics (phenology of vegetation covers and root water extraction at various soil layers) on daily soil water fluxes, including soil evaporation, surface runoff and deep percolation in generating the available soil water fraction of a given soil profile (Foale et al., 2004; Inman-Bamber and McGlinchey, 2003; McMaster et al., 2011; Wang et al., 2004; Zhang et al., 2010). 


\subsection{APSIM Input parameters}

Soil parameters

Key soil parameters required for APSIM simulations are listed in Table 2. All simulations used a consistent set of soil specific values reported for each site in APSoil (https://www.apsim.info/Products/APSoil.aspx). Those values were from previously published research. Site specific soil profile parameter values used in the present study are given in Appendix 1. Soil surface parameters and coefficients which determine surface hydraulic and energy balance were set to default values for APSoil sites. Soil depths typically varied between 100 and $160 \mathrm{~cm}$, with one site having a $280 \mathrm{~cm}$ deep soil. Computational layers varied in thickness and the number of soil layers varied between 5 and 9 . Soil moisture was analysed for the top $100 \mathrm{~cm}$, the nominal root zone, and soil layers were split into two where necessary to ensure there was a layer boundary at $100 \mathrm{~cm}$ depth.

Table 2: A list of key APSIM Soil Parameters

\begin{tabular}{ll}
\hline Parameter & Description (Units) \\
\hline BD & Bulk Density $\left(\mathrm{g} / \mathrm{cm}^{3}\right)$ \\
AirDry & Air dry water fraction $(\mathrm{mm} / \mathrm{mm})$ \\
LL_15 & Soil Permanent Wilting Point $(\mathrm{mm} / \mathrm{mm})$ \\
DUL & Drainage Upper Limit (Field capacity) $(\mathrm{mm} / \mathrm{mm})$ \\
SAT & Saturated water fraction $(\mathrm{mm} / \mathrm{mm})$ \\
Wheat LL & Wheat Permanent Wilting Point $(\mathrm{mm} / \mathrm{mm})$ \\
Wheat PASW & Plant available water $(\mathrm{mm})$ \\
Wheat KL & KL - Crop specific water extraction factor $(\mathrm{mm} /$ day) \\
Wheat XF & Crop specific root exploration/inhibitory factor \\
\hline
\end{tabular}

Initial conditions:

The initial soil water was set to $75 \%$ of capacity (out of the total water holding capacity of the soils) and the profile was filled from surface layers to the bottom layers. Other soil initial conditions (i.e. soil Nitrogen and organic matter) were left unchanged. The model was always run with 5 years of observed weather data before the start of each scenario, which is sufficient to remove the impact of these initial condition assumptions. 
Crop and Agronomic parameters:

Australian dry land cropping is dominated by winter cereals and wheat is the most widely grown crop in Australia, as well as the in the study region. Although winter cereals like wheat are generally grown in rotation with other winter crops such as canola on 3-5 year cycles, we decided to model continuous wheat cropping as we wanted to employ a relatively simple approach given the many potential crop rotation patterns. This implies that we assumed that the water use and extractions patterns of other winter crops are similar to a standard wheat crop.

In setting up crop parameters (Table 3), we followed the recommended or standard practice for each region (and for each crop variety) by the relevant authorities in Victoria and NSW (DEDJTR, 2015; Matthews et al., 2013). All sites used the recommended early planting and early maturity varieties. General practice is that winter crops are sown (crop establishment) with autumn rains. In the current modelling, sowing time was restricted to a user-defined time period (sowing window) and the sowing was triggered by a minimum amount rainfall and soil water volume in the profile. The criteria used here were a minimum rainfall amount of at least $30 \mathrm{~mm}$ within three consecutive days during the specified sowing window and a minimum profile available soil water volume of at least $200 \mathrm{~mm}$ within the crop root zone. If these conditions were not met by the end of the specified window, the crop was sown on the last day of the window, ensuring a crop for each year. In all simulations, soil nutrient levels were unlimited. 
Table 3. Agronomic details of study sites

\begin{tabular}{|c|c|c|c|}
\hline $\begin{array}{l}\text { Site } \\
\text { No }\end{array}$ & Cultivar/Variety & $\begin{array}{l}\text { Sowing } \\
\text { Density } \\
\left(\text { plants } / \mathrm{m}^{2}\right) \\
\end{array}$ & Sowing window \\
\hline 1 & \multirow{4}{*}{ Barham } & \multirow{8}{*}{100} & \multirow{4}{*}{21 Apr-15 May } \\
\hline 2 & & & \\
\hline 3 & & & \\
\hline 4 & & & \\
\hline 5 & \multirow{4}{*}{ Bolac } & & \multirow{4}{*}{ 1-Маy - 30-Маy } \\
\hline 6 & & & \\
\hline 7 & & & \\
\hline 8 & & & \\
\hline 9 & \multirow{4}{*}{ McKellar } & \multirow{4}{*}{130} & \multirow{4}{*}{ 15-Apr - 15-May } \\
\hline 10 & & & \\
\hline 11 & & & \\
\hline 12 & & & \\
\hline 13 & \multirow{2}{*}{ Bolac } & \multirow{2}{*}{120} & \multirow{2}{*}{1 May - 30 May } \\
\hline 14 & & & \\
\hline 15 & \multirow{2}{*}{ McKellar } & \multirow{5}{*}{130} & \multirow{6}{*}{ 15-Apr - 15-May } \\
\hline 16 & & & \\
\hline 17 & \multirow{4}{*}{ Wedgetail } & & \\
\hline 18 & & & \\
\hline 19 & & & \\
\hline 20 & & 120 & \\
\hline
\end{tabular}

\subsection{Simulations}

In undertaking this study two separate sets of simulations were undertaken. The first was a set of APSIM simulations at each site for the whole study period and observed weather (with a 5 year model warm-up), which was used to i) establish the modelled PASW climatology and ii) to-provide a set of synthetic observations against which to test the seasonal outlooks. The second was a large set of ensemble outlook runs. For these APSIM was batch run with the downscaled daily weather to generate soil water ensembles for a nine month period. Resultant soil water ensembles were summarized using various percentiles ${ }_{2}$ and placed in climatological context using a-soil water climatology constructed using via APSIM and the 33 year observation record at the relevant site.

Finally, the soil water ensembles were evaluated against a "truth" run of APSIM (based on observed weather) for their ability for to forecast dry (lower tercile) conditions. These were undertaken by 
warming up APSIM with 5 years of observed weather, at and then using downscaled POAMA outputs as weather forcing for a further 270 days of simulation in APSIM. For each site and each starting time, 33 outlook simulations were undertaken, resulting in a 33 member PASW ensemble derived from the 33 member downscaled POAMA ensemble. There were 396 individual starting months at each of 20 sites, resulting in 7920 individual outlooks, each of which required 33 APSIM runs, making a total of 261,360 APSIM runs to construct the ensemble outlooks.

\subsection{Data processing and Downscaling}

APSIM requires daily values for rainfall $(\mathrm{mm})$, minimum temperature $\left({ }^{\circ}{ }^{\circ} \mathrm{C}\right)$, maximum temperature $\left({ }^{\circ} \mathrm{C}\right)$, radiation $\left(\mathrm{MJ} / \mathrm{m}^{2}\right)$, and vapour pressure $(\mathrm{hPa})$. Most of the APSIM inputs were obtained simply by reformatting POAMA outputs into APSIM ready climate input files. An exception is that APSIM estimates potential evapotranspiration (PET) using (Priestley and Taylor; (1972) with minimum available inputs i.e. Net Radiation (NRad), maximum and minimum Temperature (T) and Vapour Pressure (VP). POAMA does not directly produce VP; therefore, VP was calculated from its equivalent output, the 'lower atmosphere mixing ratio' $(\omega)$ at $1.5 \mathrm{~m}$ height and the VP calculated from the mixing ratio was hydrostatically corrected for atmospheric pressure at each site climate station using standard procedures (Hartmann, 1994; Jacob, 1999; Wallace and Hobbs, 2006).

Many practical applications of climate forecast products are made at local or point scale; however, global or regional climate models are generally designed to apply at coarse scales i.e. hundreds of kilometres (Wilby et al., 2004). Both climate model biases and this scale mismatch mean that climate model output statistics can deviate significantly from point scale observation statistics. Seasonal soil water forecast products are more valuable for agricultural industries, if they can effectively be applied effectively at local or farm scales. This means that a downscaling step is required before running APSIM.

There are number of approaches that have been developed for downscaling large-scale climate variables to finer or local scale variables, often concentrating on precipitation (Benestad et al., 2008; 
Bennett et al., 2011; Frost et al., 2011; Moghim and Bras, 2017; Robertson et al., 2013; Themeß1 et al., 2011). Quantile mapping (QM) is an empirical-statistical downscaling and error correction method that has been commonly used in hydro-climatological applications to correct biases in global and regional climate simulations (Maraun, 2013; Themeß1 et al., 2012). This method has been shown to be effective at removing biases across the entire probability distribution from climate model outputs while retaining changes to rainfall frequency and variability (Ines and Hansen, 2006). Being a monotonic correction method, the QM downscaled weather variables have similar temporal and crosscorrelations as those in the climate model outputs, both within and between ensembles. As a consequence, QM does not correct any errors in these statistical structures, which are implicitly assumed to be adequately represented by the climate model.

In this study, we adopted the quantile mapping procedure described by (Themeß1 et al.-, (2012) to downscale the original $\sim 250 \mathrm{~km}$ grid scale daily weather series from POAMA to the required point location scale. For a given ASPIM-APSIM forecast period, the POAMA forecast climate data were downscaled by transposing their cumulative distribution frequency values to that those at of the same level for the site data for all days within that month of the year within the 33 year hindcast period, with the exception of the particular forecast period. That is the each-downscaling for each forecast period was based on 32 years of hindcasts and the corresponding observation record. Each of the twenty sites from Bureau climate stations (SILO data drill product) were downscaled separately. Error corrected (downscaled) time series $\left(Y_{c o r}\right)$ for each station $(i)$ were obtained by applying correction functions $(\mathrm{CF})$ to the corresponding raw POAMA $\left(X^{\text {raw }}\right)$ ensemble for the respective grid cell.

The correction function depends on the variable, lead time and given month of the outlook. Empirical cumulative density functions (ecdf) for daily observed and modelled (raw POAMA) data were constructed on a monthly basis, leaving the specific year to be corrected out, thereby ensuring the QM derivation was independent of the resulting seasonal outlooks. This approach corrects for any systematic bias in mean and variance of each individual ensemble member, but it does not correct ensemble spreads (the variation between the 33 ensemble members), which is determined by POAMA. The corrections use equation 1 . The CFs for each ensemble and each variable were developed using 
equations 2 and 3. They represent the difference between the observed (obs) and the modelled (mod) inverse ecdfs $\left(e c d f^{-1}\right)$ for the respective month in the calibration period (cal) at probability $(P)$.

$X_{t, i}^{c o r}=X_{t, i}^{r a w}+C F_{t, i}$

$C F_{t, i}=e c d f_{t, i}^{o b s, c a l^{-1}}\left(P_{t, i}\right)-e c d f_{t, i}^{\text {mod,cal }}{ }^{-1}\left(P_{t, i}\right)$

$P_{t, i}=e c d f_{t, i}^{\text {mod,cal }}\left(X_{t, i}^{r a w}\right)$

In Eqs. (1)-(3), $X_{t, i}^{\text {cor }}$ is the corrected $i^{\text {th }}$ ensemble prediction at time $t, X_{t, i}^{r a w}$ is the raw $i^{\text {th }}$ ensemble prediction at time $\mathrm{t}$ and $C F_{t, i}$ is the correction factor $i^{\text {th }}$ ensemble prediction at time $\mathrm{t}$. A range of special conditions can occur in applying this QM such as $X_{t, i}^{r a w}$ exceeding the range of the fitting data. These special conditions were all handled following the approach of (Themeß1 et al.; (2012).

\subsection{Verification and Skill assessment}

The forecast performances for rainfall, ET and $P A S W$ are-were evaluated using the Hit Rate (HR), False Alarm Ratio (FAR), Continuous Rank Probability Skill Score (CRPSS) and Probability Integral Transform (PIT) plots. We followed the procedure presented by WMO (2010) in calculating HR. The HR scores are derived from contingency tables between observations and forecasts. The HR is expressed as a ratio of the number of occasions on which the event was correctly predicted divided by the number of occasions on which the event was observed (Equation 4), that is successes divided by the number of events, where the event could be an observation below the median, for example.

$H R_{Y}=n_{c} / \mathrm{n}_{o}$

In Eq. (4), $H R_{Y}$ is the Hit Rate in forecasting the event $\mathrm{Y}$ for the variable $y$ under, $n_{c}$ is the number of correctly forecast events (e.g. forecast was for below median rainfall in January and below median rainfall was observed in January), $n_{0}$ is the number of observed events (e.g. number of times below median rainfall occurred in January). 
FAR scores are also derived from contingency tables and is are expressed as the ratio of occasions on which an event was forecast but did NOT occur divided by the number of occasions on which the event was forecast (Equation 5).

$F A R_{Y}=n_{i} / \mathrm{n}_{f}$

In Eq. (5), $F A R_{\underline{Y}}$ is the False Alarm Ratio in forecasting the event $\mathrm{Y}$ for the variable $y, n_{i}$ is the number of incorrectly forecast events, $n_{f}$ is the number of forecast events.

We also assessed the ensemble reliability using both continuous rank probability skill score (CRPSS) and probability integral transform (PIT) plots. An ensemble is reliable if the probability distribution of the ensemble members accurately reflects the uncertainty of the ensemble forecast. The ensemble forecast skill is characterised by the CRPSS following (Bennett et al.-; (2016):

$C R P S S=\frac{C R P S_{r e f}-C R P S_{F}}{C R P S_{\text {ref }}} \times 100$

where $C R P S_{F}$ and $C R P S_{\text {ref }}$ are CRPS values for the ensemble and climatology forecasts, respectively.

$\mathrm{CRPS}=\frac{1}{\mathrm{~T}} \sum_{t=1}^{T} \sum_{i=1}^{n}\left(F_{f c s t} t, i-F_{\text {obs } t, i}\right)^{2}$

where $F_{f c s t} t, i$ is the Hazen plotting position of the $i^{\text {th }}$ ensemble member at a particular site, for a particular forecast and lead time and at time $t$, and $\div n$ is the number of forecast ensemble members corresponding to the observation. Where observations are pooled across time and/or space, $T$ corresponds to the total number of pooled observations.

$F_{\text {obsv }, t, i}(I D)=\left\{\begin{array}{l}0\left(X_{t, i}<X_{t, o b s}\right) \\ 1\left(X_{t, i} \geq X_{t, o b s}\right)\end{array}\right.$

$X_{t, o b s}$ is the observation being forecast and $X_{t, i}$ is a forecast ensemble member for that variable at time $t$.

We also used PIT plots to further understand the characteristics of the ensembles. To construct a PIT plot, the probability, $F_{t}$, that $X_{t, o b s}$ corresponds to within the relevant forecast ensemble, $X_{t, i}$ where $i=1: n . F_{t}$ is calculated using an inverse percentile function. Values of $F_{t}$ are then pooled across times, 
seasons and/or sites. The pooled values of $F_{t}$ are ranked and the Hazen plotting position is calculated. Finally, $F_{t}$ is plotted against it $\underline{s}$ corresponding plotting position for all the pooled observations. If the ensemble is reliable, the resulting scatter plot should fall on the 1:1 line. Departures from the 1:1 line correspond to various issues with the statistical reliability of the forecast ensemble. The interpretation of these departures will be described in detail when discussing the relevant figures.

We undertakeook some pooling (mainly into seasons) of results to increase the statistical robustness of the verification scores and PIT plots. It should be noted that results are correlated in time and spatially, which reduces the benefit of increased sample size to some extent. The verification scores were assessed for statistical difference from the expected value for performance equivalent to using climatology ( 0.5 for hit rate and 0 for CRPSS). This was done using block bootstrapping. Block bootstrapping was used because of the correlation due to pooling of results. In the block bootstrapping resampling was done by selecting full seasons rather than individual points in the resampling step. Verification scores were assessed as statistically significant if the expected value was more extreme than either the $5^{\text {th }}$ or $95^{\text {th }}$ percentile sample from the bootstrapping. These traditional one-sided test significant significance levels were used because the hypothesis of primary interest is that the forecasting methodology here is better than using climatology.

\section{Results}

In this section, we first undertake present an evaluation of APSIM against a field trial from the region to establish confidence in the soil moisture simulations. We then provide the forecasting performances for rainfall, potential evapotranspiration (PET) and plant available soil water (PASW) outlooks across 20 stations in Victoria and New South Wales, South-East Australia as show in Figure 1. To illustrate the outlooks, we first focus on Site No. 3, which is Jil Jil, near Birchip, Victoria (Southern Mallee), Australia. This site is representative of the typical seasonal patterns across the 20 study sites and close to the median rainfall. Following this, we then use all the sites to evaluate the outlooks. 


\subsection{APSIM Evaluation}

While there are a variety of soil data sets for wheat available to us from the region, very few are both properly calibrated and monitor the full profile. We evaluated APSIM using a field data set with soil water observations for 1 season under wheat followed by 1 season under canola at the Dookie College research farm. Details of the field observations are in (Akuraju et al.- (2017). This site was simulated using the same wheat configuration as Boorhaman 1 (site 15, Tables 1 and 2), followed by an early maturing canola cultivar with 55 plants $/ \mathrm{m}^{2}$. Soil properties were specified using the APSoil Boorhaman N0554-YP soil type without any site specific site-specific calibration, and observed plant available water was calculated using lower limits determined visually from the observed moisture in each of $430 \mathrm{~cm}$ layers. The model was forced with SILO patched point data for the Dookie weather station located approximately $800 \mathrm{~m}$ from the soil water site.

Figure 2 shows time series of model predictions and observations. The sensors were installed in August 2012 but the deeper sensors $(60-120 \mathrm{~cm})$ only provided reliable data after the major wetting event in June 2013, just after the wheat was planted. From Jue 2013 onwards, the response the model tracks the observed profile plant available soil water content within $\pm 20 \mathrm{~mm}$ for wheat and $\pm 40 \mathrm{~mm}$ for canola and there is very good consistency between APSIM and the observations. The larger errors for canola are associated-due to the model lagging a little behind the spring growing season dry down. Overall these results give reasonable confidence that APSIM represents soil water dynamics satisfactorily 

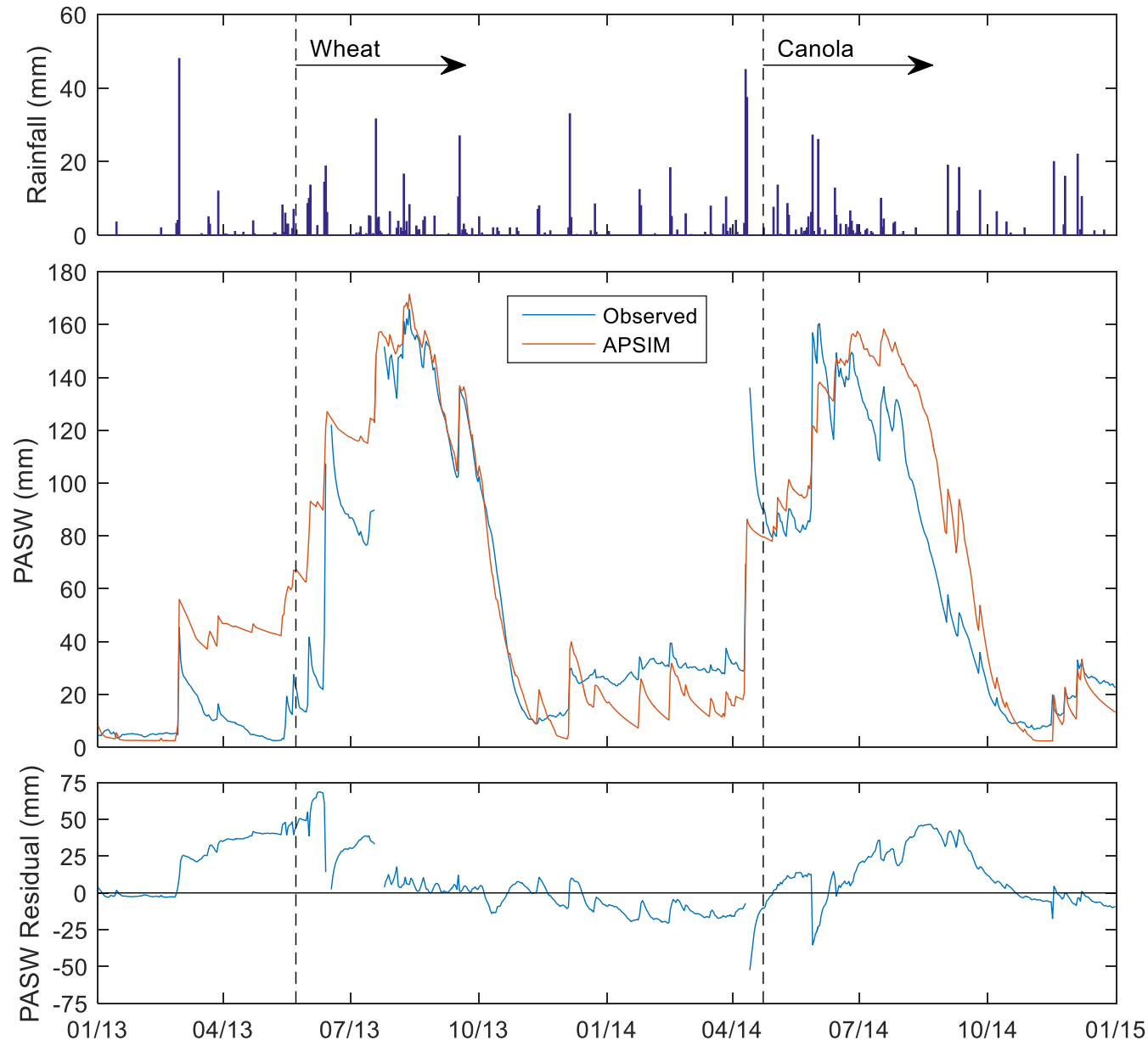

Figure 2. Evaluation of APSIM soil moisture simulation for a wheat, wheat, canola rotation at Dookie Agricultural College on a 1m deep Red Sodosol soil profile. The dashed vertical lines indicate planting dates.

\subsubsection{Climatology}

Figure $z \underline{3}$ illustrates long-term mean monthly rainfall, PET, and PASW of Site 3 (Birchip) for the 31 year period from 1981 to 2011 . The variability in monthly climate is also illustrated with box plots. There is strong seasonality for all three variables with PET closely matching insolation and rainfall $_{2}$ and $P A S W$ peaking in winter-spring. The $P A S W$ exhibits the highest monthly variability followed by rainfall, with $P E T$ only showing moderate variability. The seasonality in $P A S W$ is mainly determined by its negative relationship with $P E T$ and then by its positive relationship to rainfall. $P A S W$ has its 
lowest variability in dry periods because high PET drives PASW towards its lower bound (wilting point) during that period and the variability becomes damped. The highest variability in $P A S W$ occurs in the wetter part of the year because it is less influenced by the physical bounds on profile soil water under those conditions.

The wettest soil profiles are found from May (late autumn) to September (early spring). Typically, later autumn rains start filling the soil profile as PET declines. Low PET persists until spring due to low solar radiation and $P A S W$ peaks during July and August. PASW then starts to decline as PET increases and crop canopy increases, both of which lead to higher actual ET. PASW then remains low from November to April due to high evaporative losses and low rainfall. The highest variability in $P A S W$ is observed in the winter months and is associated with the variability in rainfall. The midwinter (July) $P A S W$ varies between 10 and $80 \mathrm{~mm}$ (95\% of the data), suggesting that long-term monthly mean $P A S W$ is unlikely to be sufficiently accurate for agricultural decisions.

The forecasting accuracy of monthly PASW is highly dependent on the reliability of rainfall and PET forecasts. The relatively high variability in rainfall compared with PET suggests that the reliability of PASW forecast will be most dependent on the forecast accuracy of rainfall rather than PET. 

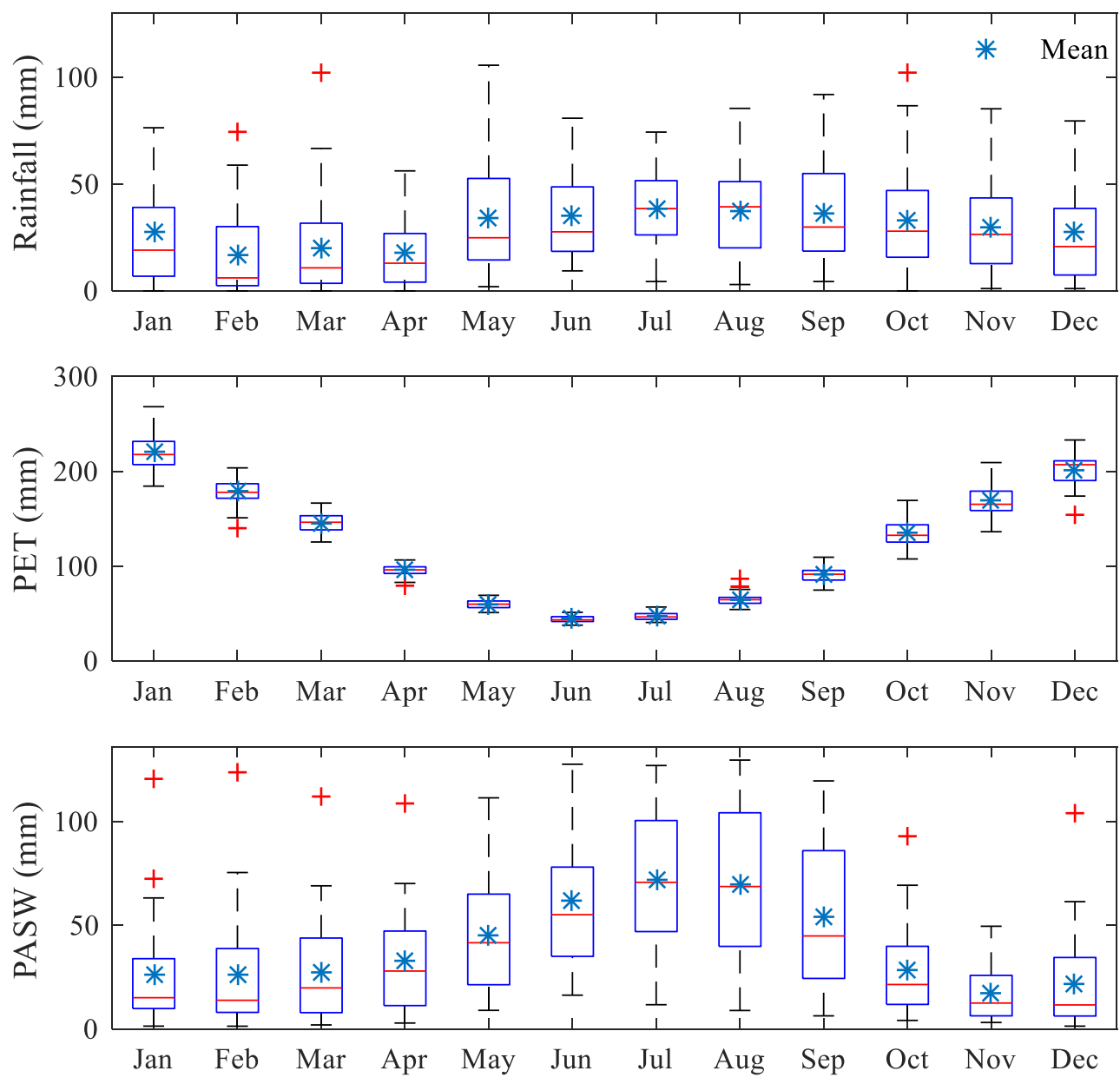

Figure $\underline{3} z$. Seasonal variation of rainfall, $P E T$ and $P A S W$ at the site 3 representing southern Mallee (Birchip, Victoria). Black Blue ** show s the mean, the red lines shows the median, the boxes shows the $25^{\text {th }}$ and $75^{\text {th }}$ percentiles ${ }_{2}$ and the whiskers extend up to 1.5 times the interquartile range. Outliers are shown with a red + .

\subsubsection{Seasonal outlooks}

We first illustrate the three-month outlook for monthly rainfall and $P A S W$ with an example outlook for the autumn months (from March to May) in 2008. Figure $3 \underline{4}$ shows the rainfall seasonal outlook for March to May 2008 for Birchip, Victoria and figure $4 \underline{5}$ shows the corresponding 3 months seasonal outlook for $P A S W$. The seasonal outlooks are overlain on the climatology shown with $10^{\text {th }}, 50^{\text {th }}$ and $90^{\text {th }}$ percentile, together with the observed time series for the last 9 months. The seasonal outlooks are 
also provided in the form of the forecast monthly tercile distribution of the 33 ensembles from POAMA (rainfall) or calculated using APSIM (PASW).

Ensemble spread for monthly rainfall and $P A S W$ gradually increases with lead time, but the spread remains within the climatology at the end of third month. In this example, the rainfall outlook follows a period (Nov-Jan) of wet months, which receive more that than median rainfall, followed by a very dry February. The tercile plot for rainfall for March 2008 indicates that $67 \%$ of ensembles are falling in the lower tercile, suggesting lower than typical rainfall for March. The rainfall outlooks for April and May 2008 show a slight tendency for wetter than typical conditions.

The PASW outlook starts with below median soil moisture as a result of the low antecedent rainfalls in February. While Nov-Jan had relatively high rainfall, this had limited impact on modelled PASW due to high PET. PASW further reduces in March 2008 due to the low rainfall forecast and then starts to increase over autumn in response to decreasing PET and increasing rainfall, with the higher rainfall ensemble members leading to relatively rapid increases in $P A S W$. Despite the wetter than average predicted conditions, the PASW forecasts are dominated by low to typical values, as indicated by the tercile plots for April and May. 

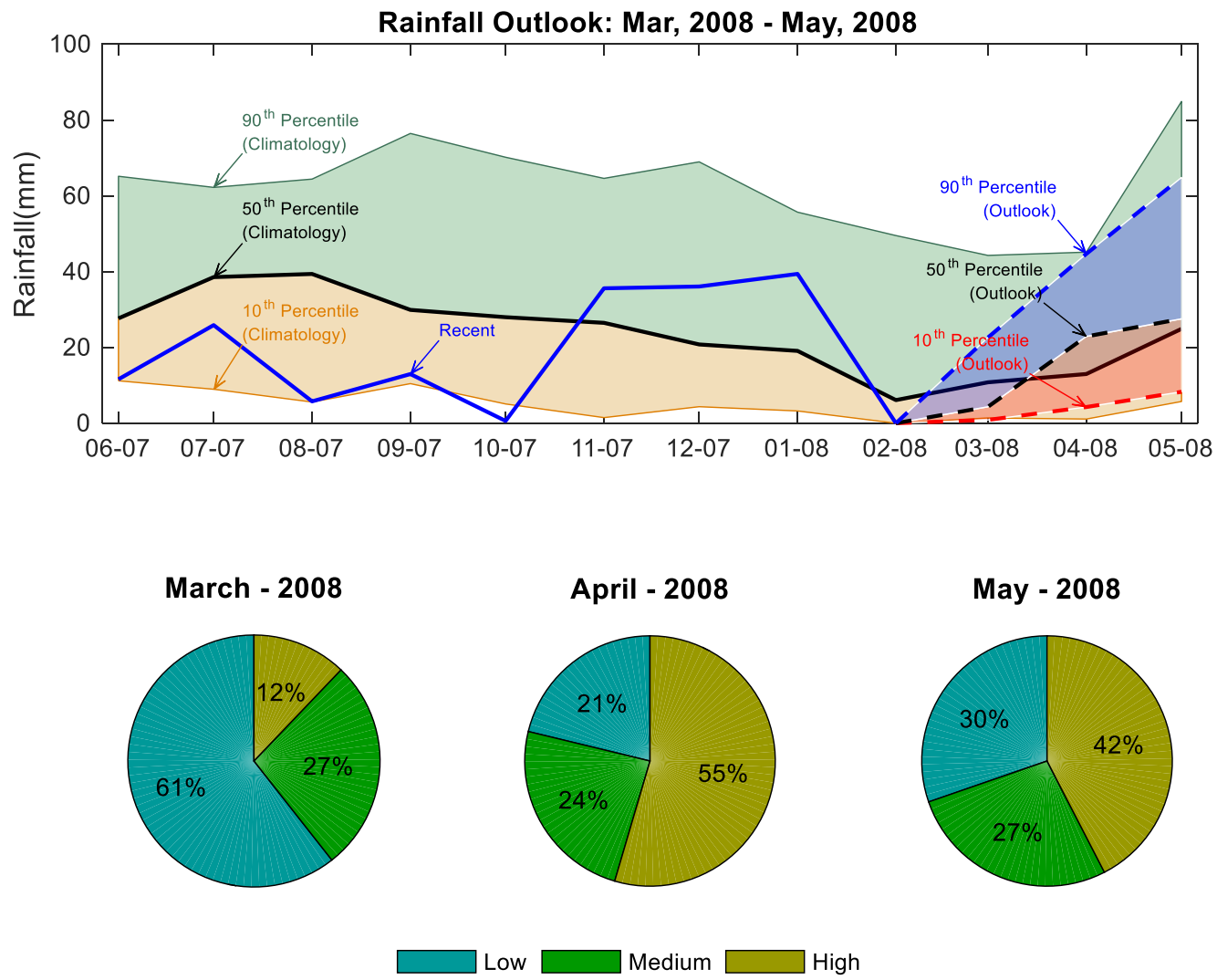

Figure 43. Monthly rainfall outlook for March to May 2008 derived from the 33 POAMA ensemble members for Birchip, Victoria. The upper panel shows the climatology with the $10^{\text {th }}-50^{\text {th }}$ and $50^{\text {th }}-90^{\text {th }}$ percentile ranges shaded fawn and green respectively. The observed rainfall for the antecedent 9 months is shown as the blue line and the rainfall outlooks for March-May are shown with the $10^{\text {th }}-50^{\text {th }}$ and $50^{\text {th }}-90^{\text {th }}$ percentile ranges shaded red and blue respectively. The lower pie diagrams show the proportion of forecast ensemble members within each climatological tercile for the three outlook months. 

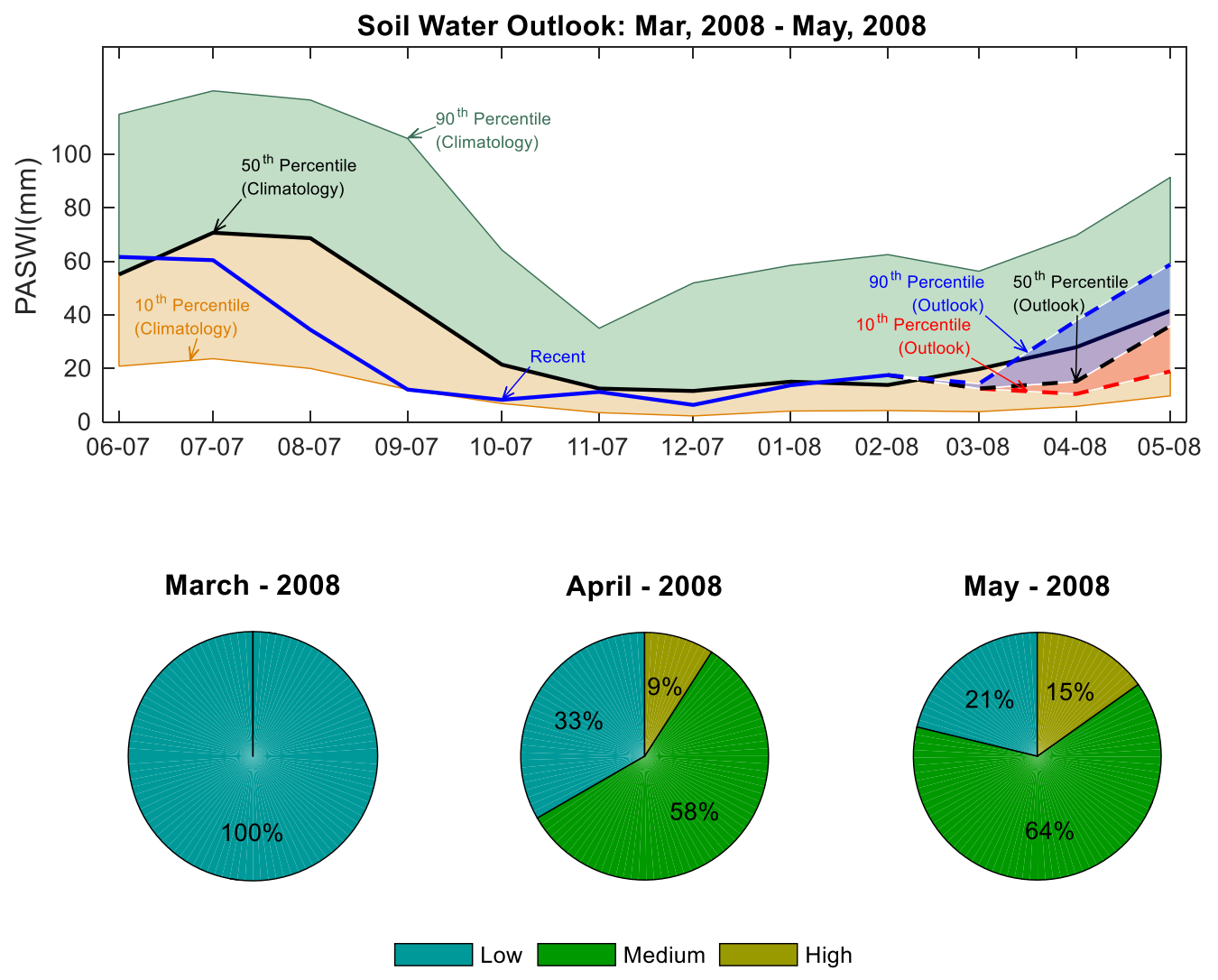

Figure 54. Monthly PASW outlook for March to May 2008 derived from the 33 POAMA ensembles downscaled and input to APSIM for Birchip, Victoria. The upper panel shows the climatology with the $10^{\text {th }}-50^{\text {th }}$ and $50^{\text {th }}-90^{\text {th }}$ percentile ranges shaded fawn and green respectively. The $P A S W$ simulated with observed rainfall for the antecedent 9 months is shown as the black-blue line and the PASW outlooks for March-May are shown with the $10^{\text {th }}-50^{\text {th }}$ and $50^{\text {th }}-90^{\text {th }}$ percentile ranges shaded red and blue respectively. The lower pie diagrams show the proportion of forecast ensemble members within each climatological tercile for the three outlook months.

\subsubsection{Forecast verification}

We now evaluate-present our evaluation of the quality of seasonal rainfall, PET and PASW outlooks across 20 sites in Victoria and NSW using Hit Rate (HR) and False Alarm Ratio (FAR). As discussed in section 2.8, we analysed the forecast performances in this section of the study. We pooled the 
individual monthly outlooks into the Austral seasons. This was done to increase the statistical robustness of the-verification scores and PIT plots. Thus, hereafter the results are reported across 4 seasons and each score value is based on 99 (33 years, 3 months) observed rainfalls, PETs or PASWs. Figure 6 s shows the HR and FAR for rainfall, PET and PASW as a function of lead time across the five regions and four seasons. The for below median conditions, and Figure 7 shows similar results for above median conditions. The below median HR is calculated as the ratio between the numbers of times both the hindcast and observation $\underline{s}$ of the respective variable fall-fell below the climatological median, divided by the total number of observations below the median observation ever during the evaluation period (1981 to 2011). An analogous approach is used for the above median HR. -A hit rate above $50 \%$ indicates better than chance performance. The below median False Alarm Ratio is the ratio between the number of times the hindcast suggests below median conditions but the observation falls on or above the median, divided by the total number of forecasts of below median conditions. A false alarm ratio below $50 \%$ indicates better than chance performance.

The mean HR across sites for below median rainfall across the regions-is in the range 575-7069\% (FAR range is 35-44\%) for a zero month lead time of one month for in all seasons. Then iIt decreases to around $55 \%(\mathrm{FAR} \approx 49 \%)$ as lead time increase to 2 months, with the exception of spring, where HR remains around $70 \%$ and FAR is around $43 \%$. The HR for above median rainfall is slightly lower and the FAR is slightly higher than for below median rainfall, which is due to some bias in the ensemble forecasts. PET hit rates are around $60-70 \%$ (FAR 35-40\%) for zero month lead time but declines (FAR increases) for longer lead times, sometimes being around 50\% (FAR 40-55\%, typically 45-50\%). Circle markers on Figures $3-\underline{6}$ and 7 indicate where the hit rate and false alarm ratio is $\underline{\text { are }}$ statistically better than chance, while crosses indicate where the hit rateperformance is statistically worse than chance. Looking at rainfall and PET combined, spring rainfalls are clearly the best in terms of forecasts of above or below median conditions. Short lead times in winter also show statistically significant performance. The fact that FAR is around or below $50 \%$ shows that the HR performance is not at the expense of false alarms, which can occur if forecasts are biased towards predicting events. 
Turning to the $P A S W$, this shows the highest HR for all lead times and all-seasons, and the forecasts are often statistically better than chance. The mean hit rate across sites varies between $\underline{77} \underline{84}-9 \underline{4} 6 \%$ (FAR range is 14-21\%) for a lead time of zero months and decreases to between $52 \underline{61-897 \%}$ (FAR range is $27-44 \%$ ) for a lead time of two months. The HR for below median conditions is consistently greater than that for above median conditions. Out of the four seasons, autumn shows the highest performance followed by winter. The HR declines more strongly in spring and summer when higher vegetation cover and greater PET lead to higher actual evapotranspiration rates and thus more rapid change in PASW. 

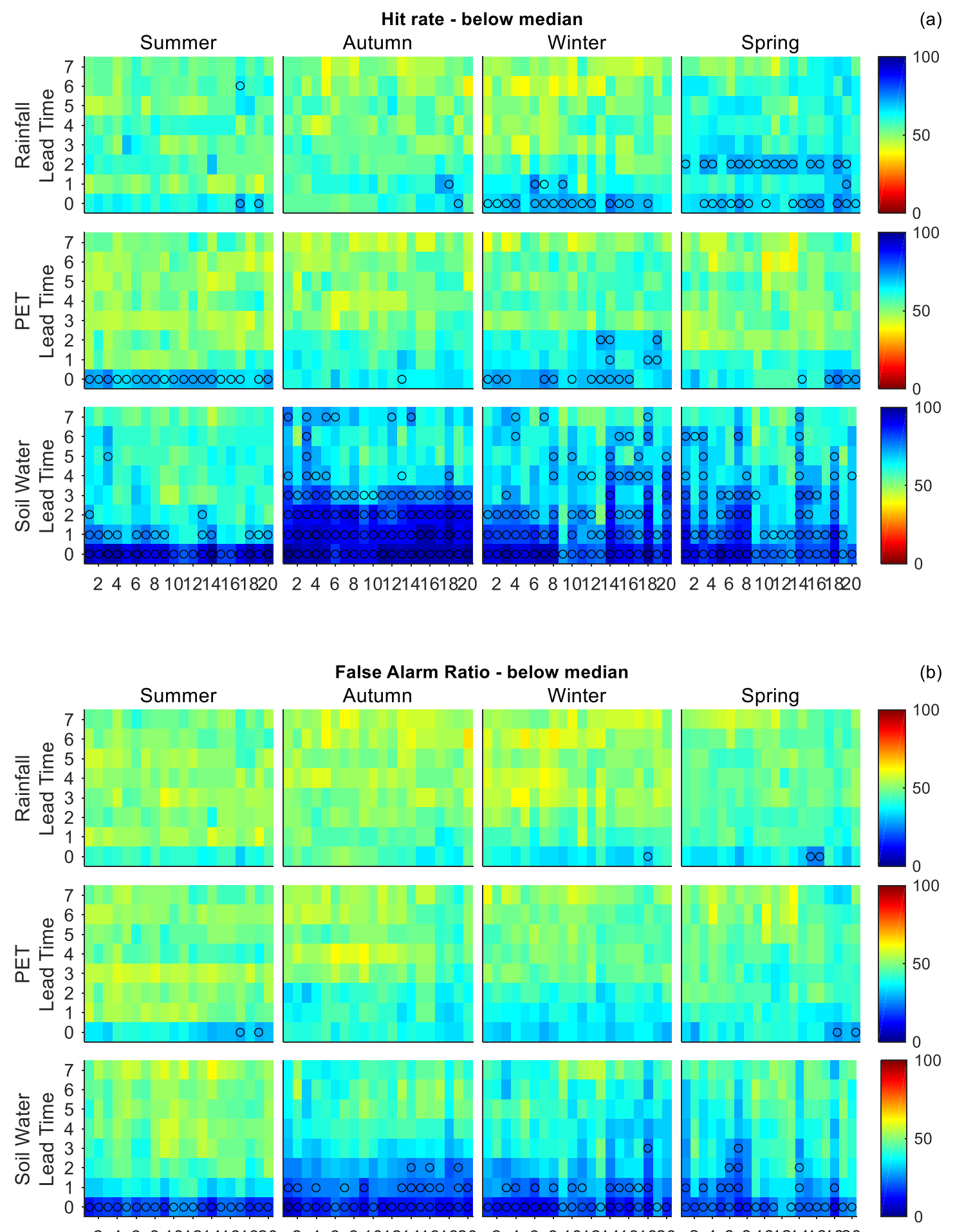

2468101214161820246810121416182024681012141618202468101214161820

Figure 65. Outlook Hit Rates and False Alarm Ratios for above and below median events for rainfall, PET and PASW forecasts for lead times of 1 to 8 months across 20 sites and four seasons. The colour scale indicates the hit rate or false alarm ratio, with blue indicating better performance. Circles indicate better than chance performance (5\% significance level), while crosses indicate statistically worse than chance performance. 


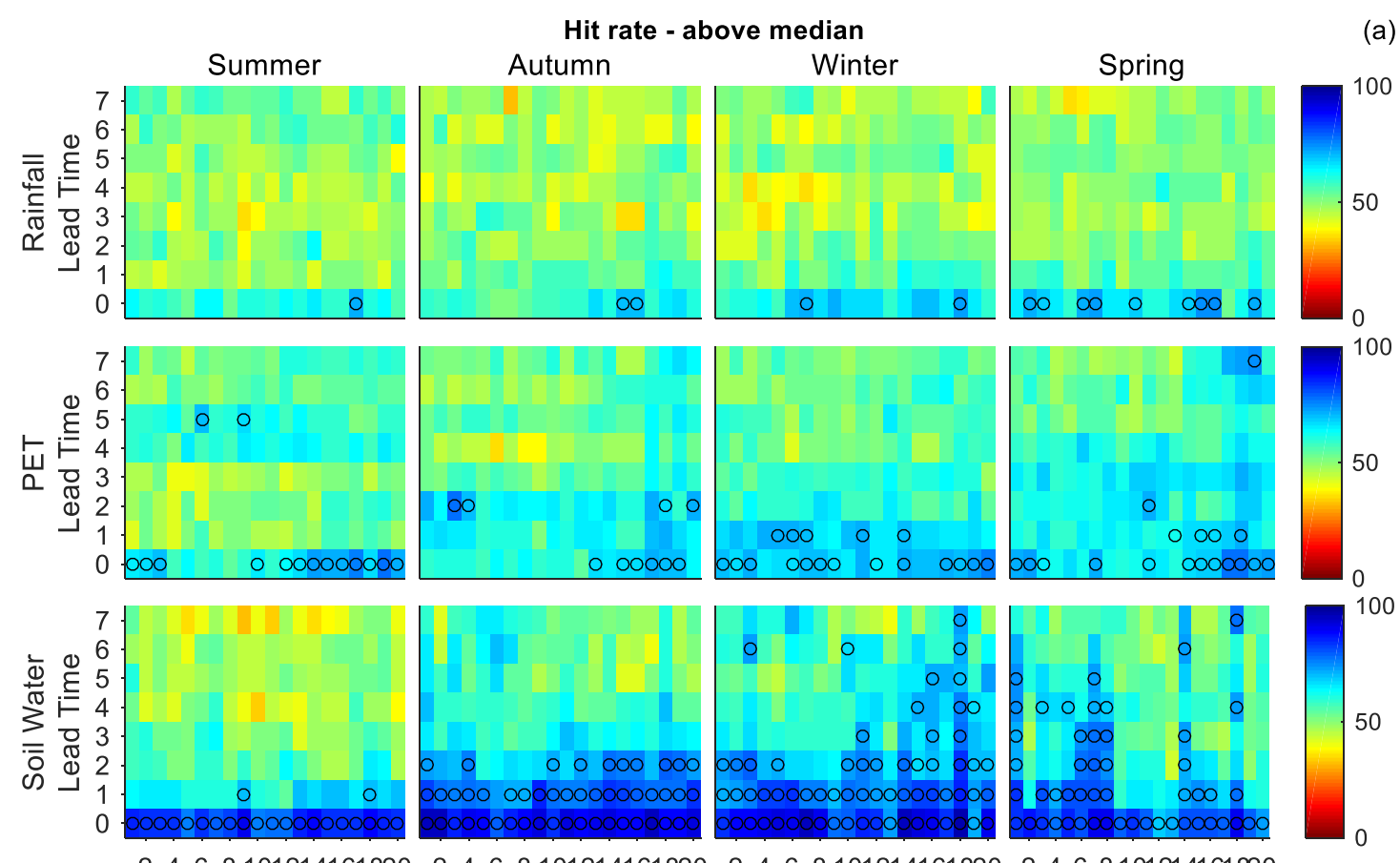

2468101214161820246810121416182024681012141618202468101214161820

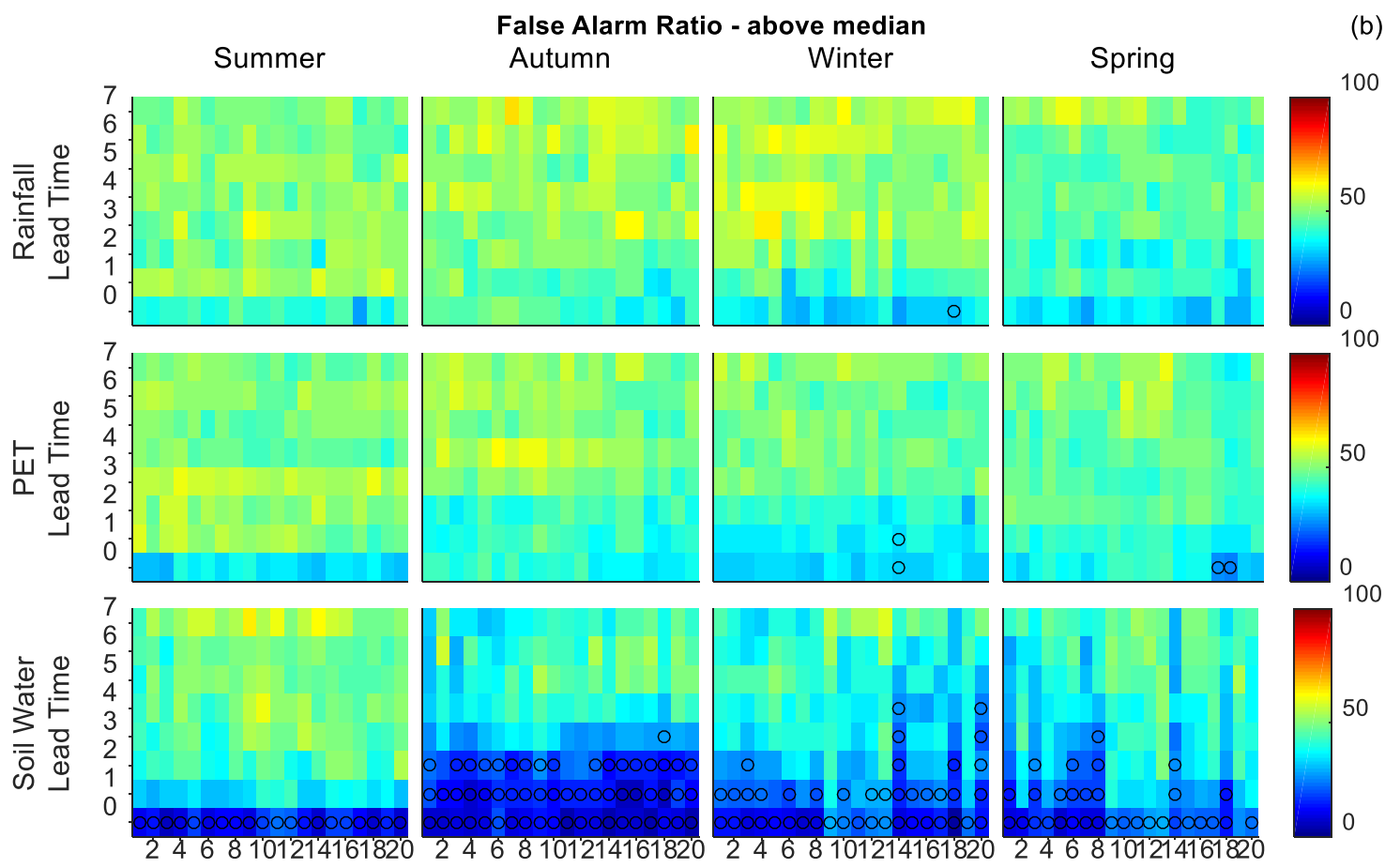

Figure 7. Outlook Hit Rates and False Alarm Ratios for above median events for rainfall, PET and $\underline{P A S W}$ forecasts for lead times of 1 to 8 months across 20 sites and four seasons. The colour scale indicates the hit rate or false alarm ratio, with blue indicating better performance. Circles indicate better than chance performance ( $5 \%$ significance level), while crosses indicate statistically worse than chance performance. 


\subsubsection{Ensemble Reliability}

The HR metric only evaluates forecasts in terms of predicting broadly drier or broadly wetter conditions. It is also useful to know how well the ensemble is representing the uncertainty in predictions. We use the Continuous Rank Probability Skill Score (CRPSS) together with Probability Integral Transform (PIT) plots to evaluate the reliability of the ensemble. Note that a forecast ensemble is said to be reliable if it correctly represents the spread in probability of the variable being forecast, indicating that the uncertainty is correctly represented.

Figure $6 \underline{8}$ shows the CRPSS for each of rainfall, PET and PASW, for each season and region. A CRPSS of zero indicates that climatology is as good a predictor as the forecast. Circles on Figure $6 \underline{8}$ indicate statistically positive skill while crosses indicate statistically negative skill, or situations where climatology is a better predictor. Generally the rainfall and PET forecasts have near zero or negative skill. This is associated with poor representation of the ensemble spread and is discussed further later. For PASW, CRPSS is generally high in the first (lead zero) month and then declines. The decline is most rapid in spring and summer when ET rates are highest due to higher PET and a denser simulated vegetation canopy (in spring).
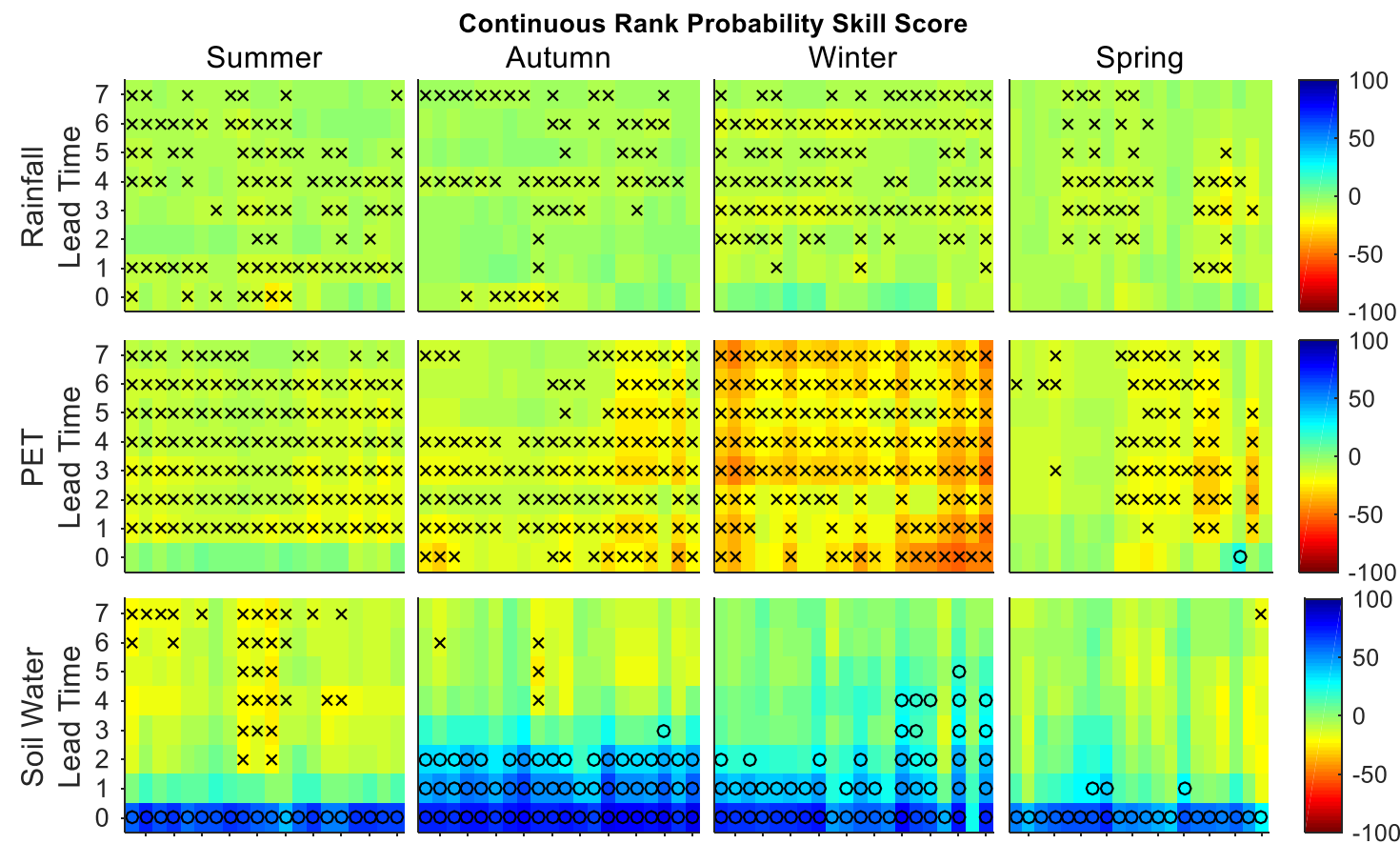

24681012141618202468101214161820246681012141618202468101214161820

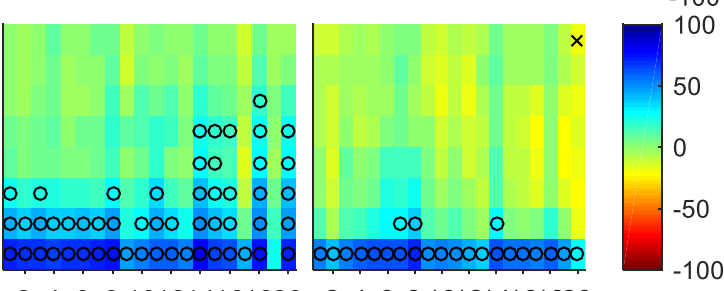


Figure 68. CRPSS for observed and ensemble monthly rainfall, PET and PASW forecasts for lead times of 1 to 8 months across 20 sites and four seasons. The colour scale indicates the CRPSS. Circles indicate better than chance performance (5\% significance level), while crosses indicate statistically worse than chance performance.

Figure 7-9 shows PIT plots for each variable and first 3 months lead times aggregated across all 20 study sites. PIT plots for each variable, first 3 months lead times and site are included in the supplementary material. The PIT plot essentially shows the relative position of the two distributions across the range of probabilities. Where the PIT falls below the 45-degree line, there are more observations below that probability than the forecast ensemble suggests, or the forecast ensemble values are generally too high. For rainfall, the PIT indicates that the lower tail of the forecast rainfalls tends to be too high. That is the observed anomalously dry months are drier than the forecast suggests. This is most pronounced in summer and for a lead time of zero months. In some cases, there is a tendency for the forecast to be lower than the observations in the central region of the distribution. The upper tails of the forecast and observation distributions generally agree.

For PET, there is a marked difference in the ensemble reliability between seasons. In summer, the forecast ensemble tends to under-estimate the observed distribution. In autumn and winter, the forecast ensemble tends to be unbiased but the spread is too large (reverse S shape), while in spring the forecast ensemble tends to over-estimate the observed distribution. There is a noticeable decline in the PET forecast reliability from 0 to 2 months lead time.

The PIT plots for $P A S W$ (Figure $7 \underline{9}$, right column) shows that the forecasts for $P A S W$ are more reliable than either rainfall or PET, with most of the curves plotting close to the 1:1 line. This is consistent with the higher values of CRPSS in Figure $6 \underline{8}$. It should be noted that the initial conditions were set using past observations and are assumed to be error free here and the results presented above would be degraded by any uncertainty in the analysis of initial conditions for the forecast. 

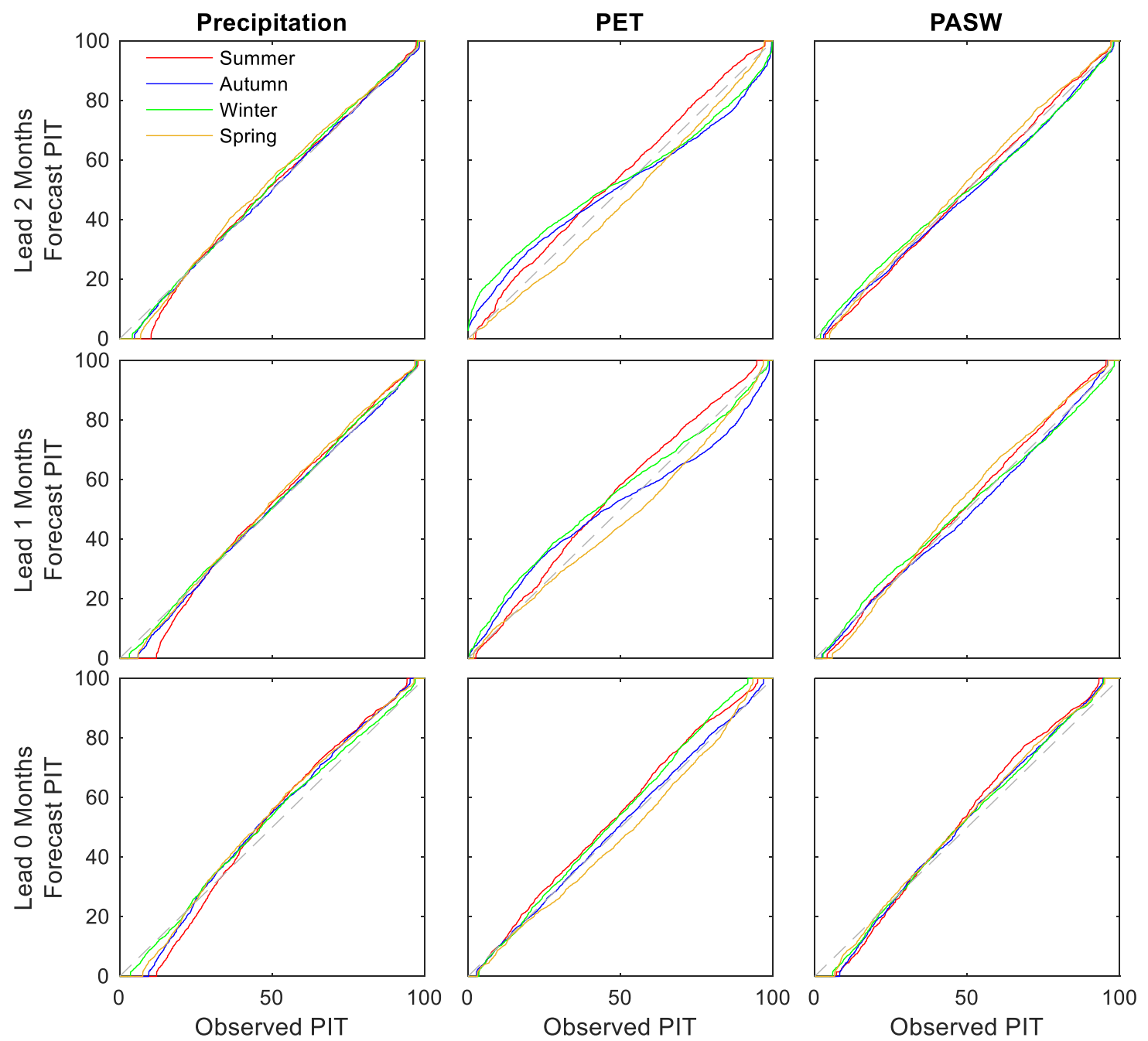

Figure 79. Probability Integral Transform plots for all sites combined. The grey dashed line shows perfect agreement. PIT values below (above) the 45-degree line indicate the forecast ensemble values are generally too high (low). An S shaped curve indicates the ensemble is too narrow and a reverse $\mathrm{S}$ shape indicates it is too wide.

\section{Discussion}

In this paper, we have developed seasonal outlooks for precipitation, PET, and Plant Available Water, for 20 sites over the South-East Australian wheat belt. These outlooks are based on seasonal forecast model runs produced by the Bureau of Meteorology, downscaling of the resultant weather variables using quantile-quantile matching and PASW simulations using APSIM. We used 33 years of POAMA hindscasts performed for the first day of each month to achieve this. Forecasts were then compared 
with simulated PASW based on observed weather data. This is one important limitation, which was enforced by a lack of existing PASW observations. Outlook ensemble performance was assessed using a combination of hit rate, continuous rank probability skill score and probability integral transform plots.

PASW seasonal outlooks have significant skill and significantly out-perform seasonal outlooks of rainfall and PET. Given the low skill (Figure $6 \underline{8}$ ) and poorer ensemble reliability (Figure 799) in the seasonal rainfall and $P E T$ forecasts combined with the quantile-quantile downscaling used at the point scale, the predictability in soil water content clearly flows from the initial conditions. It is important to note that there is a scale difference between the assessment of rainfall and PET outlooks skill here and-as used-compared to in most studies. Here we assess at the point scale rather than the atmospheric model grid scale as is typically done with climate outlooks (Hudson et al., 2013). Point scale forecasts are clearly a more challenging prospect as small-scale variation in weather impacts on our assessment. It is also expected that the new seasonal forecasting system, ACCESS-S, being developed by the Bureau of Meteorology will improve rainfall predictions skill.

Quantile-quantile matching is a relatively simple post-processing approach that has performed well for short lead times here, but leadsthat is leading to forecasts that are less reliable-poorer than climatology hereat longer lead times. Ideally a downscaling method should correct bias, produce $\underline{\text { reliable ensembles (i.e. ensembles with correct spread to represent uncertainty) and be at least as good }}$ as climatology (be "coherent") (Zhao et al., 2017). The last point reflects the idea that if forecasts are worse than climatology, it is better to just use climatology (that is history) as a guide. In fact, the CRPSS (Figure 8) is often statistically worse than using climatology at lead times longer than about 2 months. That is, the ensemble of observations from the 33 year hindcast period is a better representation of the statistical distribution of outcomes for each forecast than the forecasts themselves. For these lead times there is also no forecast skill indicated by hit rates or false alarm $\underline{\text { ratios (not statistically different to using climatology). (Zhao et al.-5(2017) recently examined quantile }}$ mapping closely and found that it performs well in correcting bias but does not guarantee reliability or coherence. Other methods, such as those used by Bennett et al. (2016), that transition to climatology 
as forecast skill declines could provide some improvement for these longer lead times but the rainfall skill levels resulting from more sophisticated post-processing are still low. Our approach could be improved by adopting more sophisticated downscaling approaches such as Bennett et al. (2016) and extending these from rainfall to all the required weather variables.

There are only a few other seasonal soil moisture forecasting studies reported in the literature. Those studies have generally not considered ensemble $P A S W$ outlooks. Our results show that the forecasting performance for ensemble $P A S W$ forecasts were generally similar to most previous studies (Dirmeyer, 2013; Spennemann et al., 2017; van den Dool et al., 2003). In particular, soil water skill clearly exceeds precipitation forecast skill and persists.

There is a marked difference between the outlook assessments based on hit rate and CRPSS, with hit

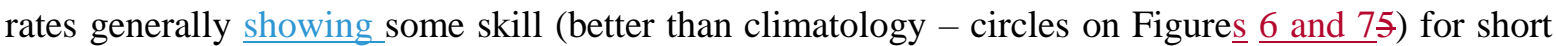
lead times and then transitioning to no skill. The CRPSS for rainfall and PET, in particular, are almost invariably negative (crosses on Figure $6 \underline{8}$ ), suggesting climatology would be better than the POAMA outlook. The key difference here is that CRPSS assesses the reliability of the ensemble distribution (location and spread), whereas hit rate is essentially concerned with the ensemble location. In general, CRPSS is negative due to issues with the shape and spread of the ensemble, and is a more challenging metric than the hit rate. It is also clear that the below median predictions have a higher hit rate than the above median predictions. This is indicative of a slight low bias in the ensemble predictions (they are low and hence more likely to be right when below average conditions occur). These observations are consistent with the shortcomings in quantile-quantile matching pointed to above.

We found that PASW outlook skill declines with lead time as uncertainty in the meteorological forcing accumulates $_{2}$ and that decline is stronger in summer and spring than in autumn and winter. The reason for this relates to the importance of initial conditions combined with the differences in SW memory timescales. SW memory can be approximated as storage/ PET (Delworth and Manabe, 1988). Figure $\underline{3} z$ shows the strong seasonality in $P E T$ driven by radiation changes. In addition to this effect, autumn is planting season and spring is the main growing season for wheat in this region, and hence the vegetation water use is much stronger in spring than autumn, for similar PET and soil water conditions. 
Thus, there is less memory in spring than in autumn. Empirical studies of the temporal scales of soil water variability in other temperate parts of the world (USA, Russia, China) have found soil water memory timescales of 2-3 months for the top $1 \mathrm{~m}$ of soil in grassland and agricultural settings (Entin et al., 2000; Vinnikov et al., 1996). Our results indicate that the skill in PASW outlooks disappeared after 2 months in spring and summer and after 3-4 months in autumn and winter, which is consistent with these empirical findings, given that the initial conditions are the key source of skill.

A number of soil moisture observation networks exist in Australia (e.g. Oznet (Smith et al., 2012), Cosmoz (Hawdon et al., 2014)) but they vary in observational methods, don't always observe the full soil profile and tend to have limited life spans due to uncertain funding. A related limitation of this current study is the lack of long-term operational soil moisture observations for the root zone. This limited our ability to validate the soil water outlooks and necessitated the use of modelled soil water for this validation analysis. Expanding systematic operational observation of rootzone PASW is critical to further evaluation of soil water analyses, forecasts and seasonal outlooks. It is important to note that depth of observation is critical. This is one of the key shortcomings of microwave remote sensing methods, which observe to the top few cms of soil. Further, because of the importance of initial moisture conditions in the outlook performance, a good quality operational network would provide opportunities to improve initialisation of soil water outlook simulations. It is likely that other benefits such as improved land surface initialisation for weather forecasts would also result. There are a number of other influences not explicitly included in this study. These include uncertainties in terms of initial soil moisture condition, soil and crop parameters, crop simulation model and crop management techniques.

\section{Conclusion}

Seasonal rainfall, PET and PASW forecasts provide decision relevant information while making seasonal agricultural production decisions. There is an opportunity to forecast seasonal rainfall, PET and PASW, by integrating outputs from seasonal forecasting models like POAMA with crop modelling simulators like APSIM. This paper quantifies the seasonal forecast performance for rainfall and PET, 
and also developed a methodology to generate probabilistic seasonal PASW forecasts combining weather variables from the Bureau of Meteorology's POAMA hindcast with APSIM for 20 sites across NSW and Victoria, Australia.

Monthly rainfall, PET and PASW were forecasted for lead times up to eight months and evaluated against observed rainfall, $P E T$ and "observed" $P A S W$ calculated using observed daily climate data for the selected 20 sites, collected from the enhanced climate database, 'SILO'. The results showed that POAMA in combination with APSIM is capable of generating seasonal PASW by using APSIM to simulate Wheat crop growth. The ensemble verification analyses indicate that $P A S W$ shows the highest seasonal forecast performances with low skill for rainfall and PET. Among seasons, autumn demenstrations-demonstrates the highest performance followed by winter, spring and summer. Our approach used quantile-quantile mapping to downscale the seasonal climate model. This approach showed a significant limitation in that it was not able to maintain skill that was at least commensurate with climatology for the rainfall and PET outlooks used to drive APSIM. There is scope to extend our analysis using other downscaling approaches that are emerging in the literature (e.g. Bennett et al., 2016).

The relatively high forecasting performance for $P A S W$ is mostly due to the impact of initial soil moisture conditions. By and large, seasonal PASW forecasts are skilful for 3 months lead time and could be used to generate decision relevant outlook products. There is an urgent need to extend operational soil water monitoring networks if such products are to be fully validated. While our study concentrated on seasonal PASW outlooks for Wheat crops, outlooks for other rain-fed crops could be developed using essentially identical methods.

\section{Acknowledgements}

This research was jointly supported by the Carlton Connect Initiative of the University of Melbourne and the Australian Bureau of Meteorology. POAMA data for this study were provided by the Australian Bureau of Meteorology. 


\section{References}

Akuraju, V.R., Ryu, D., George, B., Ryu, Y. and Dassanayake, K., 2017. Seasonal and inter-annual variability of soil moisture stress function in dryland wheat field, Australia. Agric. For. Meteorol., 232: 489-499.

Asseng, S. et al., 1998. Performance of the APSIM-wheat model in Western Australia. Field Crops Research, 57(2): 163-179.

Australian Bureau of Statistics, 2015. Agricultural Commodities, Australia, 2013-14. Released at 29/05/2015. Release No. 7121.0, Canberra. .

Benestad, R.E., Hanssen-Bauer, I. and Chen, D., 2008. Empirical-statistical downscaling. World Scientific Publishing Co Inc.

Bennett, J. et al., 2011. Performance of quantile-quantile bias-correction for use in hydroclimatological projections, MODSIM2011 International Congress on Modelling and Simulation, Perth.

Bennett, J., Wang, Q., Li, M., Robertson, D.E. and Schepen, A., 2016. Reliable long-range ensemble streamflow forecasts: Combining calibrated climate forecasts with a conceptual runoff model and a staged error model. Water Resour. Res., 52(10): 8238-8259.

BIO Intelligence Service, 2014. Soil and water in a changing environment, Final Report prepared for European Commission (DG ENV), with support from HydroLogic.

Bureau of Meteorology, 2014. National Weather and Warnings.

DEDJTR, 2015. Victorian Winter Crop Summary. Department of Economic Development, Jobs, Transport and Resources. 1835-5978. http://agriculture.vic.gov.au/_data/assets/pdf_file/0004/294727/NVT-Victoria-WinterCrop-Summary-2015.pdf.

Delworth, T. and Manabe, S., 1988. The influence of potential evapotranspiration on the variabilities of simulated soil wetness and climate. J. Clim., 1: 523-547.

Dirmeyer, P.A., 2013. Characteristics of the water cycle and land-atmosphere interactions from a comprehensive reforecast and reanalysis data set: CFSv2. Climate Dynamics, 41(3-4): 10831097.

Entin, J.K. et al., 2000. Temporal and spatial scales of observed soil moisture variations in the extratropics. J. Geophys. Res.-Atmos., 105(D9): 11865-11877.

Environmental Modeling Center, 2003. The GFS atmospheric model. National Center for Environmental Prediction Office Note, 442.

FAO, I., 2015. WFP (2015) The state of food insecurity in the world 2015, Meeting the.

Foale, M.A. et al., 2004. Participatory research in dryland cropping systems - monitoring and simulation of soil water and nitrogen in farmers' paddocks in Central Queensland. Aust J Exp Agr, 44(3): 321-331.

Frost, A.J. et al., 2011. A comparison of multi-site daily rainfall downscaling techniques under Australian conditions. J. Hydrol., 408(1-2): 1-18.

Gent, P.R. et al., 2011. The community climate system model version 4. Journal of Climate, 24(19): 4973-4991.

Geroy, I. et al., 2011. Aspect influences on soil water retention and storage. Hydrological Processes, 25(25): 3836-3842.

Hansen, J.W., 2002. Realizing the potential benefits of climate prediction to agriculture: issues, approaches, challenges. Agric. Syst., 74(3): 309-330.

Hartmann, D.L., 1994. Global Physical Climatology. Academic Press, San Diego, USA.

Haruna, S.I. and Nkongolo, N.V., 2013. Variability of Soil Physical Properties in a Clay-Loam Soil and Its Implication on Soil Management Practices. ISRN Soil Science, 2013.

Hawdon, A., McJannet, D. and Wallace, J., 2014. Calibration and correction procedures for cosmicray neutron soil moisture probes located across Australia. Water Resour. Res., 50(6): 50295043.

Hayman, P., 2011. Seasonal Climate Forecasts: Can Decision Analysis Help Agriculture? Issues(97): 19-24. 
Hayman, P., Crean, J., Mullen, J. and Parton, K., 2007. How do probabilistic seasonal climate forecasts compare with other innovations that Australian farmers are encouraged to adopt. Aust. J. Agric. Res.

Holzworth, D.P. et al., 2014. APSIM - Evolution towards a new generation of agricultural systems simulation. Environmental Modelling \& Software, 62: 327-350.

Hudson, D., Alves, O., Hendon, H.H. and Wang, G., 2011. The impact of atmospheric initialisation on seasonal prediction of tropical Pacific SST. Climate Dynamics, 36(5-6): 1155-1171.

Hudson, D., Marshall, A.G., Yin, Y., Alves, O. and Hendon, H.H., 2013. Improving Intraseasonal Prediction with a New Ensemble Generation Strategy. Monthly Weather Review, 141(12): 4429-4449.

Hunt, J. et al., 2006. Yield Prophet®: An online crop simulation service, Proceedings of the 13th Australian Agronomy Conference, pp. 10-14.

Ines, A.V. and Hansen, J.W., 2006. Bias correction of daily GCM rainfall for crop simulation studies. Agricultural and forest meteorology, 138(1): 44-53.

Inman-Bamber, N.G. and McGlinchey, M.G., 2003. Crop coefficients and water-use estimates for sugarcane based on long-term Bowen ratio energy balance measurements. Field Crops Research, 83(2): 125-138.

Isbell, R.F., 1996. The Australian Soil Classification. Australian Soil and Land Survey Handbooks, 4. CSIRO Publishing, Collingwood, Vic., Australia, 143 pp.

Jacob, D., 1999. Introduction to atmospheric chemistry. Princeton University Press.

Jeffrey, S.J., Carter, J.O., Moodie, K.B. and Beswick, A.R., 2001. Using spatial interpolation to construct a comprehensive archive of Australian climate data. Environmental Modelling \& Software, 16(4): 309-330.

Keating, B.A. et al., 2003. An overview of APSIM, a model designed for farming systems simulation. European journal of agronomy, 18(3): 267-288.

Kloss, S., Pushpalatha, R., Kamoyo, K.J. and Schutze, N., 2012. Evaluation of Crop Models for Simulating and Optimizing Deficit Irrigation Systems in Arid and Semi-arid Countries Under Climate Variability. Water Resour Manag, 26(4): 997-1014.

Maraun, D., 2013. Bias correction, quantile mapping, and downscaling: revisiting the inflation issue. Journal of Climate, 26(6): 2137-2143.

Matthews, P., McCaffery, D. and Jenkins, L., 2013. Winter crop variety sowing guide 2015. Nowra: Department of Primary Industries.

McMaster, G.S. et al., 2011. PhenologyMMS: A program to simulate crop phenological responses to water stress. Comput Electron Agr, 77(1): 118-125.

Meinke, H. and Stone, R., 2005. Seasonal and Inter-Annual Climate Forecasting: The New Tool for Increasing Preparedness to Climate Variability and Change In Agricultural Planning And Operations. Climatic Change, 70(1-2): 221-253.

Moghim, S. and Bras, R.L., 2017. Bias Correction of Climate Modeled Temperature and Precipitation Using Artificial Neural Networks. Journal of Hydrometeorology, 18(7): 1867-1884.

Nelson, R.A., Holzworth, D.P., Hammer, G.L. and Hayman, P.T., 2002. Infusing the use of seasonal climate forecasting into crop management practice in North East Australia using discussion support software. Agric. Syst., 74(3): 393-414.

Nemani, R.R. et al., 2003. Climate-Driven Increases in Global Terrestrial Net Primary Production from 1982 to 1999. Science, 300(5625): 1560-1563.

Oleson, K. et al., 2010. Technical description of version 4.0 of the Community Land Model, NCAR Tech, Note NCAR/TN-478+ STR, 257.

Paull, C., 2002. The value and benefits of using seasonal climate forecasts in making business decisions: a review. Department of Primary Industries.

Peel, M.C., Finlayson, B.L. and McMahon, T.A., 2007. Updated world map of the Köppen-Geiger climate classification. Hydrology and Earth System Sciences 11: 1633-1644.

Priestley, C.H.B. and Taylor, R.J., 1972. On the Assessment of Surface Heat Flux and Evaporation Using Large-Scale Parameters. Monthly Weather Review, 100(2): 81-92.

Probert, M., Dimes, J., Keating, B., Dalal, R. and Strong, W., 1998. APSIM's water and nitrogen modules and simulation of the dynamics of water and nitrogen in fallow systems. Agricultural Systems, 56(1): 1-28. 
Robertson, D.E., Shrestha, D.L. and Wang, Q.J., 2013. Post-processing rainfall forecasts from numerical weather prediction models for short-term streamflow forecasting. Hydrol. Earth System Sci., 17(9): 3587-3603.

Seneviratne, S.I. et al., 2010. Investigating soil moisture-climate interactions in a changing climate: A review. Earth-Science Reviews, 99(3): 125-161.

Sharma, K., 2011. Rain-fed agriculture could meet the challenges of food security in India. Curr Sci, 100(11): 1615-1616.

Smith, A.B. et al., 2012. The Murrumbidgee soil moisture monitoring network data set. Water Resour. Res., 48(7): 6pp.

Spennemann, P.C., Rivera, J.A., Osman, M., Saulo, A.C. and Penalba, O.C., 2017. Assessment of Seasonal Soil Moisture Forecasts over Southern South America with Emphasis on Dry and Wet Events. Journal of Hydrometeorology, 18(8): 2297-2311.

Themeß1, J.M., Gobiet, A. and Heinrich, G., 2012. Empirical-statistical downscaling and error correction of regional climate models and its impact on the climate change signal. Climatic Change, 112(2): 449-468.

Themeß1, M., Gobiet, A. and Leuprecht, A., 2011. Empirical-statistical downscaling and error correction of daily precipitation from regional climate models. International Journal of Climatology, 31(10): 1530-1544.

Tippett, M.K., Barnston, A.G. and Robertson, A.W., 2007. Estimation of seasonal precipitation tercilebased categorical probabilities from ensembles. Journal of climate, 20(10): 2210-2228.

van den Dool, H., Huang, J. and Fan, Y., 2003. Performance and analysis of the constructed analogue method applied to US soil moisture over 1981-2001. Journal of Geophysical Research: Atmospheres, 108(D16).

Vinnikov, K.Y., Robock, A., Speranskaya, N.A. and Schlosser, C.A., 1996. Scales of temporal and spatial variability of midlatitude soil moisture. J. Geophys. Res., 101(D3): 7163-7174.

Wallace, J.M. and Hobbs, P.V., 2006. Atmospheric science: an introductory survey, 92. Academic press.

Wang, E.L., Smith, C.J., Bond, W.J. and Verburg, K., 2004. Estimations of vapour pressure deficit and crop water demand in APSIM and their implications for prediction of crop yield, water use, and deep drainage. Australian Journal of Agricultural Research, 55(12): 1227-1240.

Wang, J., Wang, E., Luo, Q. and Kirby, M., 2009. Modelling the sensitivity of wheat growth and water balance to climate change in Southeast Australia. Climatic Change, 96(1): 79-96.

Western, A.W., Grayson, R.B. and Blöschl, G., 2002. Scaling of soil moisture: a hydrologic perspective. Annual Review of Earth and Planetary Sciences, 205: 20-37.

Wilby, R. et al., 2004. Guidelines for use of climate scenarios developed from statistical downscaling methods. Supporting material of the Intergovernmental Panel on Climate Change, available from the DDC of IPCC TGCIA, 27.

WMO, 2010. Manual on the global data-processing and forecasting system, Volume I - Global aspects. World Meteorological Organization Document WMO-No. 485. [Available online at http://www.wmo.int/ pages/prog/www/DPFS/documents/485_Vol_I_en_colour.pdf].

Yin, Y., Alves, O. and Oke, P.R., 2011. An Ensemble Ocean Data Assimilation System for Seasonal Prediction. Monthly Weather Review, 139(3): 786-808.

Zhang, H.W., Chen, H.L., Zou, C.H. and Yu, W.D., 2010. The Review of Dynamic Monitoring Technology for Crop Growth. Proc Spie, 7809.

Zhao, T. et al., 2017. How Suitable is Quantile Mapping For Postprocessing GCM Precipitation Forecasts? J. Clim., 30(9): 3185-3196. 


\section{University Library}

\section{- M M N E R VA A gateway to Melbourne's research publications}

Minerva Access is the Institutional Repository of The University of Melbourne

\section{Author/s:}

Western, AW;Dassanayake, KB;Perera, KC;Argent, RM;Alves, O;Young, G;Ryu, D

Title:

An evaluation of a methodology for seasonal soil water forecasting for Australian dry land cropping systems

\section{Date:}

2018-05-01

\section{Citation:}

Western, A. W., Dassanayake, K. B., Perera, K. C., Argent, R. M., Alves, O., Young, G. \& Ryu, D. (2018). An evaluation of a methodology for seasonal soil water forecasting for Australian dry land cropping systems. AGRICULTURAL AND FOREST METEOROLOGY, 253, pp.161-175. https://doi.org/10.1016/j.agrformet.2018.02.012.

Persistent Link:

http://hdl.handle.net/11343/297391 